\title{
The novel-molecule T11TS facilitated arousal of glioma-mediated dormancy of bone-marrow hematopoietic stem-cells
}

\begin{abstract}
Somnath Mondal',2, Ankur Datta ${ }^{1,2}$, Iman Hazra', Sk Md Omar Faruk1, Saibal Moitra1, Suhnrita Chaudhuri", Lakshyajeet Nath ${ }^{1}$, Prasanta Kumar Das ${ }^{1}$, Anjan Kumar Basu4, Santanu Kumar Tripathi², Swapna Chaudhuri ${ }^{1}$

'Department of Laboratory Medicine, Calcutta School of Tropical Medicine, Kolkata 700073, West Bengal, India.

${ }^{2}$ Department of Clinical \& Experimental Pharmacology, School of Tropical Medicine, Kolkata 700073, West Bengal, India.

${ }^{3}$ Centre for Tumour Biology, Barts Cancer Institute, Queen Mary University of London, Charterhouse Square, London EC1M, UK. ${ }^{4}$ Department of Biochemistry and Medical Biotechnology, School of Tropical Medicine, 108 C. R. Avenue, Kolkata 700073, West Bengal, India.
\end{abstract}

Correspondence to: Prof. Swapna Chaudhuri, Department of Laboratory Medicine, Calcutta School of Tropical Medicine, 108 C. R. Avenue, Kolkata 700073, West Bengal, India. E-mail: swapna.chaudhuri@gmail.com

\begin{abstract}
How to cite this article: Mondal S, Datta A, Hazra I, Omar Faruk SM, Moitra S, Chaudhuri S, Nath L, Das PK, Basu AK, Tripathi SK, Chaudhuri S. The novel-molecule T11TS facilitated arousal of glioma-mediated dormancy of bone-marrow hematopoietic stem-cells. Neuroimmuno/ Neuroinflammation 2018;5:34. http://dx.doi.org/10.20517/2347-8659.2018.13
\end{abstract}

Received: 27 Mar 2018 First Decision: 14 May 2018 Revised: 10 Aug 2018 Accepted: 14 Aug 2018 Published: 30 Aug 2018

Science Editor: Athanassios P. Kyritsis Copy Editor: Huan-Liang Wu Production Editor: Cai-Hong Wang

\begin{abstract}
Aim: T11TS, a potent anti-gliomagenic glycoprotein, stimulates both peripheral and intracranial immune response. The status of bone marrow hematopoietic stem cells (BMHSCs), the cradle of regeneration of all blood cells, during gliomagenic global immune devastations has not yet been investigated. Therefore, we aimed to delineate the effects of T11TS on immature and mature compartments of hematopoietic machinery.
\end{abstract}

Methods: Flowcytometric analysis of cultured BMHSCs was evaluated for assesing the expression pattern of early hematopoietic stem cells (HSCs) markers such as CD34+ ${ }^{+}$Sca-1 $1^{+}$, c-kit $^{+}$and also Angiopoietin- 1 and Tie-2 both in normal, glioma, and in T11TS treated glioma-bearing animals. Immunofluresenece imaging and western blot analyses of BMHSCs were also carried out.

Results: There was significant downregulation of HSCs-markers CD34 ${ }^{+}, \mathrm{Sca}^{-1}{ }^{+},{\mathrm{c}-k i t^{+}}^{+}$in ethyl nitrosourea-induced gliomabearing animals followed by an increase in the expression level of Ang-1 and Tie- 2 that determines the quiescence and self-renewability of stem cells. T11TS administration reversed the gliomagenic transformation of expression of the above mentioned markers. The results flowcytometric-analysis was also well corroborated with immunofluorescence imaging and western blot analysis.

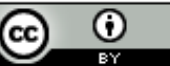

(C) The Author(s) 2018. Open Access This article is licensed under a Creative Commons Attribution 4.0 International License (https://creativecommons.org/licenses/by/4.0/), which permits unrestricted use, sharing, adaptation, distribution and reproduction in any medium or format, for any purpose, even commercially, as long as you give appropriate credit to the original author(s) and the source, provide a link to the Creative Commons license, and indicate if changes were made.

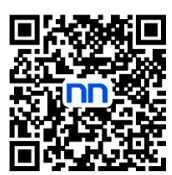


Conclusion: Collectively, the above experimental evidence hints towards gliomagenic maneuver of receptor expression of HSCs to derange the systemic immunity and T11TS mediated manipulation towards revival/rejuvenation of the same.

Keywords: Glioma, immunosupreesion, T11TS, immunotherapy, hematopoietic stem cells, immunophenotyping, immunomodulation

\section{INTRODUCTION}

Systemic depression of cellular immunity and subsequent global immune suppression is the classical poor prognostic fact of gliomagenesis ${ }^{[1]}$. Debilitating gliomas evade the host immune surveillance either by adopting immune-editing strategies such as impairment of antigen presenting machinery ${ }^{[2]}$, activation of negative co-stimulator signals for example cytotoxic T-lymphocyte-associated protein 4 (CTLA4), B7 homolog 1/programmed death 1 (PD1) and Programmed death-ligand 1 (PDL1) ${ }^{[3-5]}$ and recruitment of proapoptotic pathway [e.g., Fas receptor, Fas ligand (FasL) $]^{[6]}$, expansion of regulatory $\mathrm{T}$ cell population ${ }^{[7]}$ and down regulation or absence of tumor specific antigen ${ }^{[8]}$ or by secreting cytokines such as interleukin 10 (IL-10), interleukin 6 (IL-6), transforming growth factor beta 1 (TGF- $\beta$ ), prostaglandin E2 (PGE2), and various gangliosides which have been implicated for their direct immune suppressive role to diminish the antitumor immune response during glioma progression ${ }^{[9-11]}$.

Interestingly, gliomagenic generation of potent immune suppressors in addition acts as intense inhibitory regulators of hematopoiesis by modulating the function of bone marrow hematopoietic stem cells (BMHSCs) ${ }^{[1,213]}$. TGF- $\beta$, a key negative regulator of hematopoiesis not only suppresses in vitro proliferation of both progenitors and mature stem cells but also induces quiescent state of functional hematopoietic stem cells (HSCs) ${ }^{[14,15]}$. Malignant brain tumor derived gangliosides inhibited hematopoiesis at different stages of differentiation and resulted in bone marrow hypoplasia ${ }^{[16,17]}$. PGE2 regulates hematopoiesis in a dose and time-dependent manner and modulates hematopoiesis as negative and positive feedback control ${ }^{[18,19]}$. The immunosuppressive, IL-10 is found to contribute its inhibitory impact in hematolymphopoiesis during various pathological conditions ${ }^{[20,21]}$.

Viewing HSCs as the foundation for the immune response ${ }^{[22]}$ we hypothesize that global immune suppression during glioma progression might have an important deleterious bearing on synchronized internal signaling network of hematopoietic machinery that regulates HSCs homeostasis, proliferation, and migration. However, there is an iota of literature about the status of bone marrow-derived HSCs during glioma condition and/or immunotherapeutic modulation of HSCs. There has been little success in preventing destructive nature of glioma either by modulating glioma stem cells or by using genetically engineered stem cells in glioma therapy ${ }^{[23,24]}$.

HSCs are delineated by their propensity for self-renewal and differentiation into entire committed hematopoietic lineages. With few exceptions, proper functioning of early hematopoietic stem and progenitor cells are dependent on c-kit, stem cell antigen-1 (Sca-1) and CD34 mediated signalling system for their self-renewal, proliferation, and survival $^{[25-27]}$. On the other hand, Angiopoietin-1 (Ang-1) and tyrosine-protein kinase receptor (Tie-2), the two important cell surface markers maintain homeostasis of HSCs by regulating molecular crosstalk between HSCs and bone marrow niche and protect HSCs from pathological conditions ${ }^{[28,29]}$.

The novel immunomodulatory glycopeptide, T11 target structure/Sheep-Lymphocyte function-associated antigen-3/CD58 (T11TS/SLFA-3/S-CD58) ${ }^{[30]}$, has been delineated in our lab for its multipotent anticancer activities against $\mathrm{N}$-ethyl-N-nitrosourea (ENU) induced glioma-bearing rat model and also in vitro human glioma samples ${ }^{[31]}$. Typically T11TS mediated eradication of glioma is due to the simultaneous rejuvenation of peripheral and intracranial immune system which was profoundly suppressed due to gliomagenic secretion of immunosuppressive cytokines such as IL-10, TGF- $\beta$, IL-4, and PGE2, etc. T11TS imparts immune-potentiation by activating T-lymphocytes ${ }^{[32]}$, NK cells $^{[33]}$, macrophage $(\mathrm{M} \Phi)^{[34]}$, Neutrophils ${ }^{[30]}$ 
and microglial cells ${ }^{[35]}$. A recent finding by our lab also documented that T11TS favors $\mathrm{T}$ cells survival not only by inhibiting glioma mediated apoptogenic death of $\mathrm{T}$ cells $\mathrm{s}^{[36]}$ but also by repairing gliomagenic impairment of phosphatidylinositol 3-kinase/AKT (PI3K-AKT) signaling cascades ${ }^{[37]}$. Further study in our lab also deciphered that T11TS immunotherapy, mediate functional activation of $\mathrm{T}$ cells by rectifying gliomagenic anti-proliferative action on T-cell by correcting CD2-mediated nuclear factor of activated T-cell calcineurin pathway ${ }^{[38]}$. Some of our previous publications also delineated that T11TS reduces glioma mass simultaneously by accelerating the apoptotic death of brain tumor cells and by decreasing the number of dividing glioma-bearing cell $^{[39,40]}$.

The above immune rejuvenation and induced increased potentiality during T11TS treatment might have an important bearing on the concomitant production of activated immunocompetent cells through the hematopoietic machinery in the bone marrow. The query for such regenerative immunocompetence remains unanswered on the hematopoietic level. Interestingly, in our recent publication, we have elucidated for the first time that T11TS also protects the BMHSCs by inhibiting the premature apoptogenic death by counteracting gliomagenic stimulation of intrinsic, extrinsic apoptogenic pathway and also by inhibiting Granzyme-B mediated apoptotic fate of HSCs within bone marrow milieu ${ }^{[41]}$.

Hence, the present study emphasized on possible modulations of key elements of the early phases of hematopoiesis on bone marrow HSCs during glioma growth and following T11TS therapy. Our finding shows modulatory effects of T11TS therapy towards differentiation, proliferation, activation of HSCs against gliomagenic shock. This entirely new finding not only illuminates the role of HSCs in glioma and also the relevance of T11TS therapy against this dreadful disease, but it may also drive us towards an important new target for basic investigation and, potentially, therapeutic intervention against many more hematological malignancies.

\section{METHODS}

\section{Animals}

Healthy Swiss albino rat pups of both sexes (4.5-6 g) were maintained in our Institutional animal facility as per Institutional Ethical Committee guidelines monitored by Committee for the Purpose of Control and Supervision of Experiments on Animals, Govt. of India regulations ${ }^{[41]}$. Six animals in each group were weaned at 1 month of age and housed in individual cages at $22{ }^{\circ} \mathrm{C}$ in a $12 \mathrm{~h} \mathrm{light/dark} \mathrm{cycle.} \mathrm{Animals} \mathrm{were}$ fed with standard autoclaved food pellets along with water ad libitium.

The experimental animals were grouped into the following 5 groups: (1) age matched normal healthy control [N]; (2) 3-5 days-old neonatal animals intraperitoneally (i.p.) injected with ENU and reared for 5 months (optimal period for glioma development) [ENU]; (3) ENU animals (5 months of age) treated with single dose of (i.p.) T11TS [ET1]; (4) ENU animals treated with 2 doses of (i.p.) T11TS [ET2] at an interval 6 days for each dose; (5) ENU animals treated with 3 doses of (i.p.) T11TS [ET3] at an interval 6 days for each dose.

\section{Brain tumor induction with ethyl nitrosourea}

ENU the engineered alkylating compound is a strong mutagen and is observed to be the most intense of neurocarcinogens engendering brain tumors with architectural and physiological likenesses to typically ensuing neural neoplasms in mankind ${ }^{[42]}$. ENU does not require any metabolic computation for its enactment ${ }^{[43]}$. ENU can enter into brain in spite of an intact blood brain barrier and the alkylated products of the DNA are readily formed within the brain tissue $e^{[44]}$.

ENU was freshly prepared by dissolving $10 \mathrm{mg} / \mathrm{mL}$ in sterile saline and adjusting the $\mathrm{pH}$ to 4.5 with crystalline ascorbic acid. ENU was injected i.p. to newborn rats (3-5 days old) with a dose of $80 \mathrm{mg} / \mathrm{kg}$ body weight ${ }^{[36]}$. Maintenance of age-matched control was done by rearing healthy rat pups up to 5 months of age. 


\section{Isolation of T11TS}

The glycopeptide T11TS/SLFA-3 was isolated from sheep red blood cell (SRBC) membrane. Briefly, SRBC was trypsinized, and after nonspecific protein precipitation by TCA, was subjected to ion exchange chromatography on a DEAE cellulose column, with a five-chambered gradient system. Finally, elute fraction III was selected as the fraction of choice.

\section{Administration of T11TS in animals}

The first dose of $1 \mathrm{~mL}$ of T11TS was administered in rats intraperioneally (i.p.) from the third elute fraction (EF III), which was followed by a second booster dose on the sixth day and the third booster dose on the day 12, making a dose schedule of 1,2 and $3 \mathrm{~mL}$ to the ET1, ET2 and ET3 animals, respectively ${ }^{[36,45]}$.

\section{Isolation of HSC from bone marrow}

From the long bones (femur, tibia, and fibula) bone marrow was isolated as described previously ${ }^{[41,46]}$. A single cell suspension in an aseptic condition was prepared from the bone marrow. The cells were subjected to centrifugation at $1000 \mathrm{rpm}$ for $20 \mathrm{~min}$ on a bi-layered Percoll density gradient namely 1.077 at the bottom and 1.050 at the top. Cells obtained from the top [i.e. low-density compartment (LDC)] and bottom [i.e. high-density compartment (HDC)] layers were collected separately and washed thrice in PBS followed by culturing in RPMI media as described and characterized by Chatterjee et al. ${ }^{[46]}, 2010$.

\section{Short-term stem cell culture}

The LDC and HDC cells were cultured and maintained for 5 days in a $75 \mathrm{~mm}$ culture dish (Corning, USA) containing $4 \mathrm{~mL}$ of RPMI-1640 supplemented with $10 \% \mathrm{FBS}, 100 \mathrm{ng} / \mathrm{mL}$ of SCF, $20 \mathrm{ng} / \mathrm{mL}$ of IL3 at $37^{\circ} \mathrm{C}$ in an atmosphere of $5 \% \mathrm{CO}_{2}$ as described by Mondal et al. ${ }^{[41]}, 2018$.

\section{Effect of T11TS on the phenotypic markers of HSCs}

Bone marrow-derived isolated LDC and HDC cells of all groups were taken from 5-day cultures on the 6th day and were subjected to flowcytometric analysis. Percentage of extracellular CD34, Sca-1 and c-kit, Ang-1 and Tie-2 population in LDC and HDC cells were evaluated using primary antibodies against CD34 (BD Biosciences, USA), Sca-1 (Abcam Inc., USA), c-kit, Ang-1 and Tie-2 (Santa Cruz Biotechnology Inc, USA) respectively followed by $\mathrm{PE}$-conjugated anti-rat respective monoclonal antibodies for $30 \mathrm{~min}$ as described by Mondal et al. $.^{[41]}, 2018$ with little modification. FACS Calibur (BD Biosciences) with Cell Quest Pro software was used for acquisition and analysis of percent cellular expression of each protein as quantified. A total of 10,000 events were acquired and analyzed for each sample. Gating was performed with respect to the individual group of the unstained control sample. Values indicated in "section 3 " are the mean of six individual studies with S.D. calculated oneach mean value.

\section{Immunofluorescence imaging of cells}

Short term cultured HSCS grown overnight on the poly L-lysine coated sterile cover slips at $37^{\circ} \mathrm{C}$ were fixed with $4 \%$ paraformaldehyde in PBS for 20 min. After blocking, the cells were incubated overnight with anti-primary Ang-1, Tie-2, CD34, and c-kit antibody [1:250 dilutions in PBS with 1\% bovine serum albumin (BSA)] at $4{ }^{\circ} \mathrm{C}$. After washing with PBS, CD34 and c-kit tagged cells were incubated with FITC secondary antibody and anti-Ang-1 and Tie-2 tagged cells were incubated with TRITC conjugated secondary antibody (1:500 dilutions in PBS with 1\% BSA). The rest of the procedures such as staining of the nucleus with DAPI, visualization, capturing of images and quantification and representation of data were done as described ${ }^{[41,47]}$. Briefly, Nis-Elements D3.00 were used for capturing images and quantification. Each condition was observed in triplicate and six images were taken for each sample. Figures are representative of the group. Results were expressed as mean fluorescence intensity of number total cells positively stained by the desired fluorescence tagged protein out of the total number of cells counted for each experimental group. Figures are representative of the group. As a negative control, primary antibody was omitted. 


\section{Statistical analysis}

Data shown are representative of six independent experiments $(n=6)$ and values are expressed as mean \pm SD unless otherwise stated. For statistical comparison, the one-way analysis of variance was performed followed by application of the Tukey's post-hoc test. A $P$ value $<0.05$ was considered to be statistically significant.

\section{RESULTS}

Bone marrow-derived CD $34^{+}$cell, Sca-1+ ${ }^{+}$cell and c-kit ${ }^{+}$cell, Ang-1 cell and Tie-2 cell: density specific compartmentalization

During our phenotyping characterization of HSCs from the bone marrow, densitometric centrifugation technique resulted in two well distinct categories of cells. Cells at LDC (1.050) indicate immature HSCs and the other at HDC (1.077) denote mature HSCs ${ }^{[48]}$, which will lead to the generation of the progenitors. The harvested cells were subjected to CD34, Sca-1, c-kit, Ang-1, and Tie-2 positivity in a cell sorter.

\section{Effect of T11TS on the phenotypic markers CD34 of BMHSCs}

Bone marrow-derived $\mathrm{CD} 34^{+}$-enriched cell population claimed to be one of the most critical markers for $\mathrm{HSCs}^{[49]}$ and their expression is down-regulated as they differentiate into mature cells ${ }^{[50]}$. Single staining was done for $\mathrm{CD} 34$. Flowcytometric analysis [Figure $1 \mathrm{~A}$ and $\mathrm{B}$ ] showed a higher enrichment of $\mathrm{CD} 34^{+}$cells in the LDC level than in the HDC. In normal rats, there was a higher level of expression of CD34 both in the LDC and HDC in comparison to the ENU treated glioma-bearing rat where BMHSCs showed a significantly ( $P$ $<0.001)$ decreased level of expression both in the LDC and HDC. However, there was a very significant $(P<$ $0.001)$ increase in expression levels of both in the LDC and HDC in all three dose levels, i.e., ET1, ET2 and ET3 in T11TS treated glioma-bearing rats.

In situ immunofluorescence imaging studies [Figure $1 \mathrm{C}$ ] further confirmed the CD34 FACS findings. In the ENU group, the majority of $\mathrm{CD} 34^{+}$cells showed a significant $(P<0.001)$ decrease in their expression of fluorescence intensity both in the LDC and $(1.692 \pm 0.439)$ in the HDC as compared to the normal group in both compartments. The intensity gradually increased following T11TS therapy in dose dependent manner ET1. ET2 and a significant up-regulation were noted at the third dose, i.e., ET3 in both the LDC and HDC compartments.

\section{Effect of T11TS on the phenotypic markers Sca-1 of BMHSCs}

Sca-1, an important marker of emerging HSCs, regulates the overall developmental program of HSCs towards self-renewal, lineage fate and c-kit expression ${ }^{[25,51]}$.

Flowcytometric studies [Figure 2A and B] showed that there was significant down regulation $(P<0.001)$ of Sca-1 expression both in the LDC and HDC (in glioma-bearing rats as compared to the normal groups in both the LDC and HDC. Following T11TS therapy, there was significant up-regulation $(P<0.001)$ of the expression of Sca-1 at all dose levels (ET1, ET2 and ET3) both in the immature and mature compartments compared to glioma-bearing groups. Immunoblot data [Figure $2 \mathrm{C}$ and $\mathrm{D}$ ] corroborated the flowcytometric finding and confirmed that the expression of Sca-1 increased significantly $(P<0.0001)$ in dose-dependent manner in glioma associated BMHSCs of T11TS treated groups both in the LDC and HDC compared to that in HSCs of glioma-bearing ENU group both in LDC and HDC.

\section{Changes in the expression pattern of c-kit following T11TS therapy}

$\mathrm{C}-\mathrm{Kit}$, a tyrosine kinase receptor for stem cell factor, acts as a unique marker for $\mathrm{HSCs}^{\left[{ }^{[2]}\right.}$ and regulates the fate of $\mathrm{HSCs}^{[53]}$. Even small changes in the expression pattern of c-kit resulted in dramatic phenotypes and profoundly altered the developmental rhythm of hematopoiesis ${ }^{[54]}$.

Flowcytometric studies showed [Figure 3A and B] that following glioma induction, expression of c-kit in BMHSCs of ENU group, there was a remarkable $(P<0.001)$ decrease in the expression level, both in LDC 
A

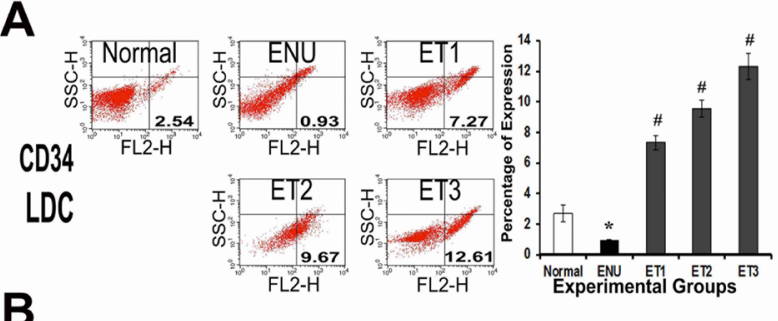

B

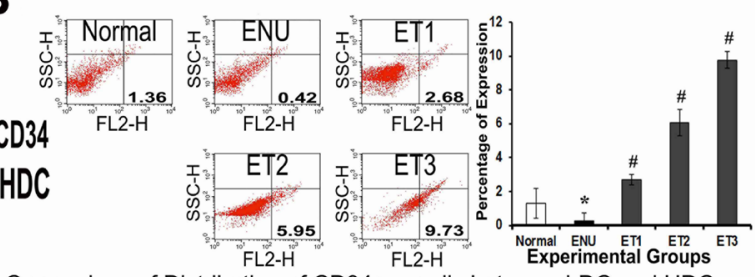

Comparison of Distribution of CD34+ve cells between LDC and HDC
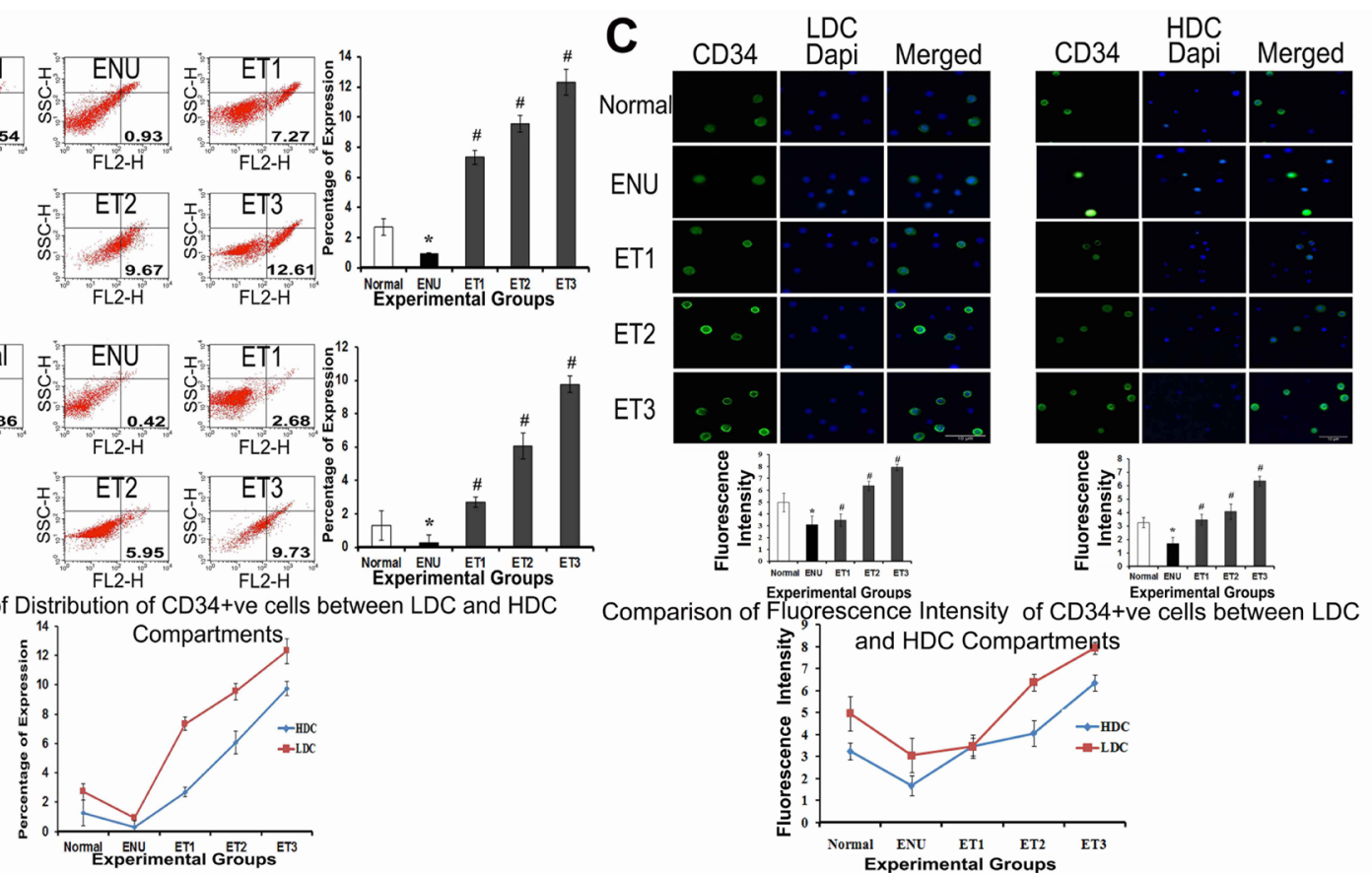

Comparison of Fxperimental Groups

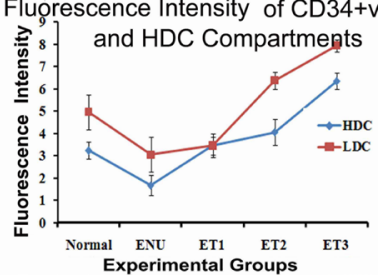

Figure 1. Comparative study of expression of CD34 in HSCs of five experimental animal groups, viz., normal, healthy control rats (N), glioma-bearing rats (ENU), and rats having received the first (ET1), second (ET2) and third (ET3) doses of T11TS. Flowcytometric studies of the expression of CD34 in HSCs cells isolated from bone marrow of normal control and of glioma-bearing rats before and after T11TS treatment have been shown. A: Flowcytometric analysis of CD34 percent positive cells in the LDC using BD Cell Quest Pro Software by using scatter from a single representative experiment. The percentage of the expression refers to the percent positive cells out of 10,000 cells analyzed represented in graphical form in bar diagram. Column values represent mean \pm SD ( $n=6$ animals per group); B: Flowcytometric analysis of CD34 percent positive cells in the HDC using BD Cell Quest Pro Software by using scatter from a single representative experiment. The percentage of expression refers to the percent positive cells out of 10,000 cells analyzed represented in graphical form in bar diagram. Column values represent mean \pm SD $\left(n=6\right.$ animals per group). Comparison of Distribution of CD34 ${ }^{+}$ Cells between LDC and HDC: The line diagram shows both the LDC and HDC HSCs there is a steep high rise in their expression level of CD34 $4^{+}$cells following T11TS administration, but compared to HDC the LDC cells show the high level of proliferation as compared to ENU and normal groups probably hinting arousal of HSCs from niche as CD34 expressed mainly in primitive HSCs; C: representative images (100× magnification) showing immunofluorescent staining of cell surface CD34 expression on bone marrow derived hematopoietic stem cells of normal (N) and glioma-bearing rats before (ENU) and after T11TS treatment (ET1, ET2 and ET3) in both the LDC and HDC compartments. Each condition was observed in triplicate and six images were taken for each sample. Figures are representative of the group. Results were expressed as the percent CD34-positive cells out of the total number of cells counted for each experimental group. Column CD34: FITC-stained CD34 expression in bone marrow derived hematopoietic stem cells green in color due to the presence of CD34. Column DAPI: nuclei appear blue due to staining with DAPI. Column merged: FITC-stained fluorescence intensity of each group was analyzed with Nikon's Nis - Elements D3.00 software and the mean intensity was expressed in bar diagrams. Individual bar values represent mean fluorescence intensity $\pm S D$ of the respective group. At the bottom the comparison of the mean fluorescence intensity of CD34 positive cells between LDC and HDC has been also depicted. ${ }^{*}$ Significant $(P<0.001)$ decrease in ENU compared with that of normal control group. " Significant $(P<0.001)$ increase, when individually comparing T11TS treated groups with glioma-bearing ENU group in both the compartments. HSCs: hematopoietic stem cells; LDC: low density compartment; HDC: high density compartments; ENU: N-ethyl-N-nitrosourea

and HDC. T11TS administration in glioma-bearing animal significantly $(P<0.001)$ up-regulated c-kit expression in glioma associated BMHSCs of both the groups in all three dose levels both in the mature and immature compartments as compared to the significantly low expression in the ENU induced gliomabearing group.

Immunofluorescence imaging studies also confirmed our findings. Immunofluorescence staining and imaging [Figure $3 \mathrm{C}$ ] of cytoplasmic c-kit expression of bone marrow-derived hematopoietic stem cells were evident from robust $(P<0.001)$ decrease in cytoplasmic mean fluorescence intensity observed in bone marrow-derived hematopoietic stem cells of ENU group both in the LDC and HDC. Normal bone marrow-derived hematopoietic stem cells showed moderate fluorescence staining and hence medium 
A

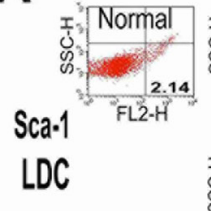

B

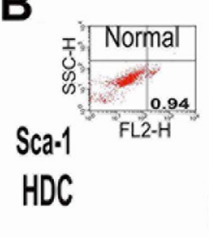

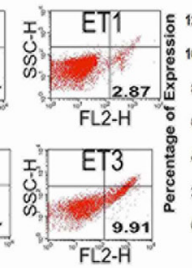

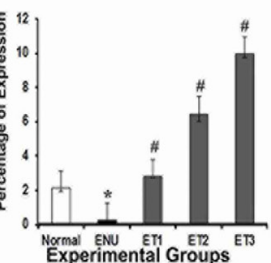

Experimental Groups

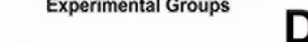

D

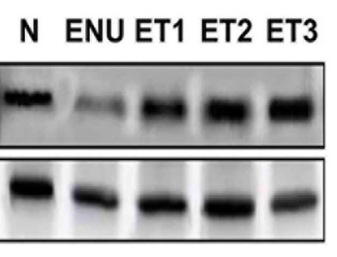

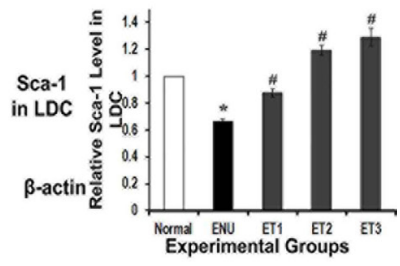

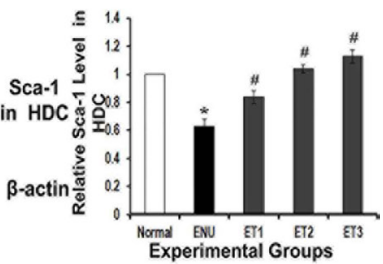

Experimental Groups

Comparison of Relative Sca-1 Level between LDC and HDC

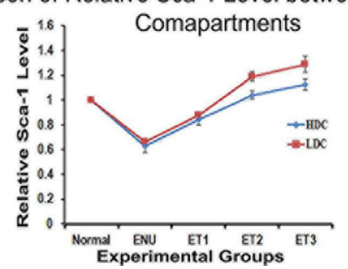

Figure 2. Comparative study of expression of Sca-1 in HSCs of five experimental animal groups, viz., normal, healthy control rats (N), glioma-bearing rats (ENU), and rats having received the first (ET1), second (ET2) and third (ET3) doses of T11TS. Flowcytometric studies of the expression of Sca-1 in HSCs cells isolated from bone marrow of normal control and of glioma-bearing rats before and after T11TS treatment have been shown. A: Flowcytometric analysis of Sca-1 percent positive cells in the low density compartment using BD Cell Quest Pro Software by using scatter from a single representative experiment. The percentage of expression refers to the percent positive cells out of 10,000 cells analyzed represented in graphical form in bar diagram. Column values represent mean \pm SD $(n=6$ animals per group); B: Flowcytometric analysis of Sca-1 percent positive cells in the high density compartment (HDC) using BD Cell Quest Pro Software by using scatter from a single representative experiment. The percentage of expression refers to the percent positive cells out of 10,000 cells analyzed represented in graphical form in bar diagram. Column values represent mean $\pm \operatorname{SD}$ ( $n=6$ animals per group). Comparison of Distribution of Sca-1 $1^{+}$cells between LDC and HDC: The line diagram shows both the LDC and HDC HSCs there are a steep high rise in their expression level of Sca-1 cells after T11TS administration, but compared to HDC the LDC cells show the high level of proliferation as compared to ENU and Normal groups probably hinting activated state of HSCs towards further maturity since Sca1 expressed in both primitive and mature cells; C: Expression of Sca-1 in LDC was analyzed by immunoblotting using anti-Sca-1 specific antibody. The immunoblot shows band intensities for the Sca-1. $\beta$-actin was used as loading control and blots were reprobed with anti- $\beta$ actin antibody to establish equivalent loading. Bands were individually analyzed densitometrically and relative pixel intensities of individual, group were displayed in bar diagrams; D: expression of Sca-1 in HDC was analyzed by immunoblotting using anti-Sca-1 specific antibody. The immunoblot shows band intensities for the Sca-1. $\beta$-actin was used as loading control and blots were reprobed with anti- $\beta$ actin antibody to establish equivalent loading. Bands were individually analyzed densitometrically and relative pixel intensities of individual, group were displayed in bar diagrams. ${ }^{*}$ Significant $(P<0.001)$ decrease in ENU compared with that of normal control group. \#Significant $(P<0.001)$ increase, when individually comparing T11TS treated groups with glioma-bearing ENU group. At the bottom, the comparison of expression of relative pixel intensities of Sca- $1^{+}$cells between LDC and HDC. HSCs: hematopoietic stem cells; LDC: Iow density compartment; HDC: high density compartments; ENU: N-ethyl-N-nitrosourea

mean intensity both in the LDC and HDC. T11TS treatment caused a significant $(P<0.001)$ increase in cytoplasmic c-kit expression in glioma-associated BMHSCS in all ET1, ET2 and ET3 groups, in dose dependent manner both in the LDC and HDC compared to that in hematopoietic stem cells of gliomabearing ENU group in both the compartments.

\section{Modulation of Tie-2/Ang-1 signaling of bone marrow-derived hematopoietic stem cells}

Regulatory role of Ang-1/Tie-2 signaling pathway during maturation of HSCs under various pathological stresses and correlation of activation of this pathway with quiescence state of HSCs within the bone marrow niche is gradually emerging. The status of maintenance of HSC at quiescence not only determines the lifelong self-renewing ability of HSC but also enhances their survivability by optimizing cell division ${ }^{[28]}$. In addition, up regulated Ang-1/Tie-2 signaling is believed to impart in the long-term repopulating ability of $\mathrm{HSCs}^{[55]}$. 


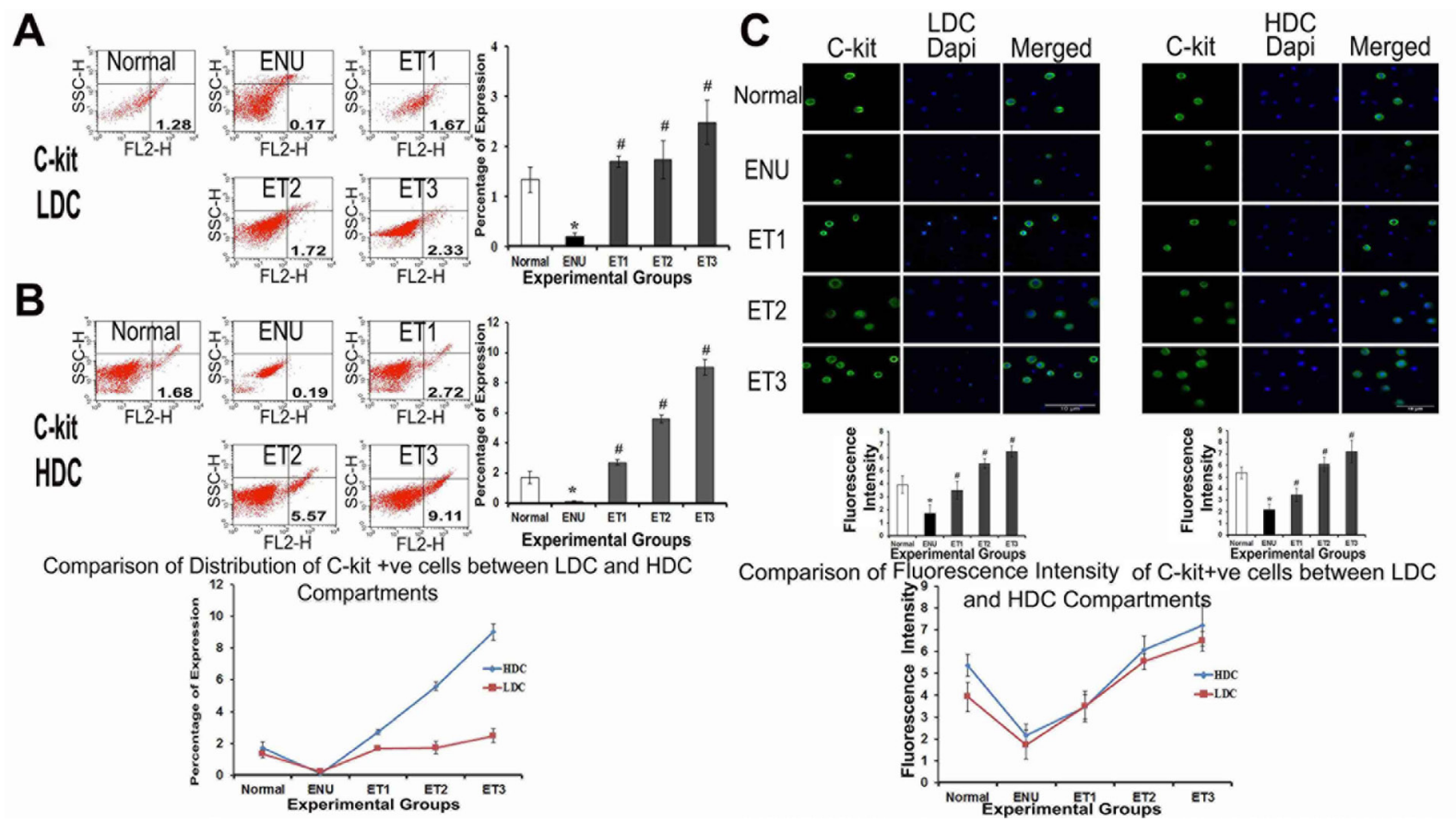

Figure 3. Comparative study of expression of c-kit in HSCs of five experimental animal groups, viz., the normal, healthy control rats (N), glioma-bearing rats (ENU), and rats having received the first (ET1), second (ET2) and third (ET3) doses of T11TS. Flowcytometric studies of the expression of c-kit in HSCs cells isolated from bone marrow of normal control and of glioma-bearing rats before and after T11TS treatment have been shown. A: Flowcytometric analysis of c-kit percent positive cells in the LDC using BD Cell Quest Pro Software by using scatter from a single representative experiment. The percentage of expression refers to the percent positive cells out of 10,000 cells analyzed represented in graphical form in bar diagram. Column values represent mean \pm SD ( $n=6$ animals per group); B: Flowcytometric analysis of c-kit percent positive cells in the high density compartments (HDC) using BD Cell Quest Pro Software by using scatter from a single representative experiment. The percentage of expression refers to the percent positive cells out of 10,000 cells analyzed represented in graphical form in bar diagram. Column values represent mean $\pm \mathrm{SD}$ ( $n=6$ animals per group). Comparisonof Distribution of c-kit ${ }^{+}$Cells between LDC and HDC. The line diagram shows both the LDC and HDC HSCs there is a steep high rise in their expression level of c-kit cells after T11TS administration, but compared to HDC the LDC cells shows the high level of proliferation as compared to ENU and normal since c-kit ligation opens up SCF signaling cascade which leads to lineage commitment of HSCs, so the results obtained here with also hints driving of both the group of cells towards lineage commitment; C: representative images (100× magnification) showing immunofluorescent staining of cell surface c-kit expression on bone marrow derived hematopoietic stem cells of normal $(N)$ and glioma-bearing rats before (ENU) and after T11TS treatment (ET1, ET2 and ET3) in both the LDC and HDC compartment. Each condition was observed in triplicate and six images were taken for each sample. Figures are representative of the group. Results were expressed as the percent c-kit-positive cells out of the total number of cells counted for each experimental group. Column C-kit: FITC-stained c-kit expression in bone marrow derived hematopoietic stem cells green in color due to the presence of c-kit. Column Dapi: Nuclei appear blue due to staining with DAPI. Column Merge: Merged image FITC-stained fluorescence intensity of each group was analyzed with Nikon's Nis - Elements D3.00 software and the mean intensity was expressed in bar diagrams. Individual bar values represent mean intensity \pm SD of the respective group. At the bottom the comparison of the mean intensity of c-kit positive cells between LDC and HDC has been also depicted. *Significant $(P<0.001)$ decrease in ENU compared with that of normal control group. "Significant $(P<0.001)$ increase, when individually comparing T11TS treated groups with glioma-bearing ENU group in both the compartments. HSCs: hematopoietic stem cells; LDC: low density compartment; HDC: high density compartments; ENU: N-ethyl-N-nitrosourea

Flowcytometric studies showed [Figure $4 \mathrm{~A}$ and $\mathrm{B}$ ] that following glioma induction Ang-1 expression BMHSCs of the ENU group in both the LDC and HDC compartments was remarkably $(P<0.001)$ elevated compared to low basal expression in normal BMHSCs in both the LDC and HDC. T11TS treatment in glioma model, significantly $(P<0.001)$ inhibited Ang-1 expression in glioma associated BMHSCs of LDC and HDC at all three (ET1, ET2 and ET3) dose levels in both the compartments as compared to the remarkably high expression in ENU group both in the LDC and HDC.

Relative band intensities of immunoblot experiment showed [Figure $4 \mathrm{C}$ and $\mathrm{D}$ ] that expression of Ang-1 decreases significantly in BMHSCs both in the LDC and HDC in T11TS treated glioma associated BMHSCs in dose-dependent manner as compared to the significantly high level of expression in ENU induced glioma- 
A

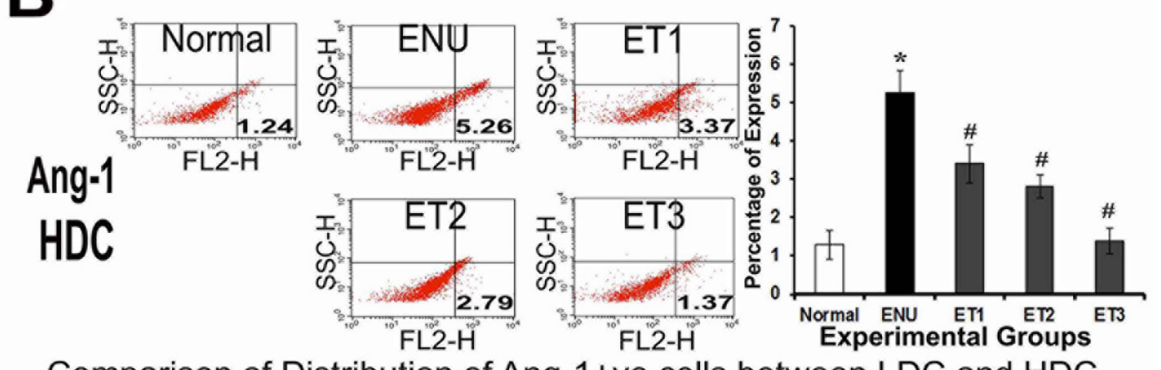

Comparison of Distribution of Ang-1+ve cells between LDC and HDC

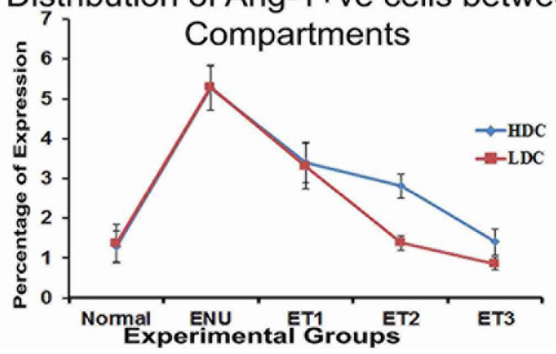

C

\section{N ENU ET1 ET2 ET3}
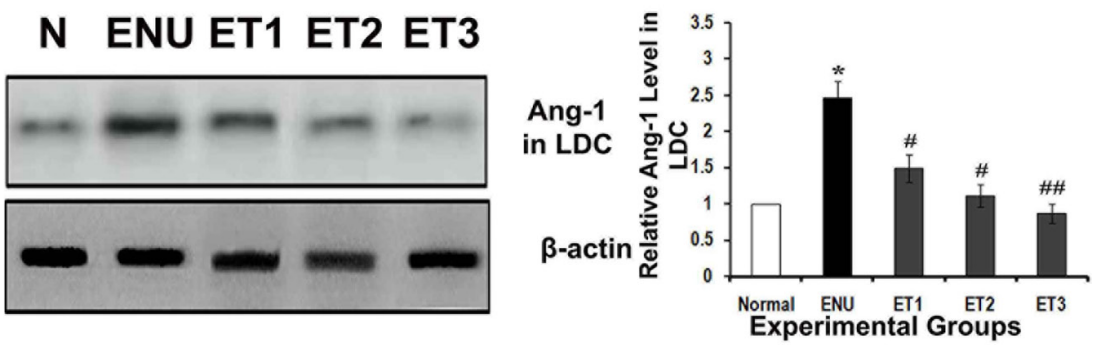

D
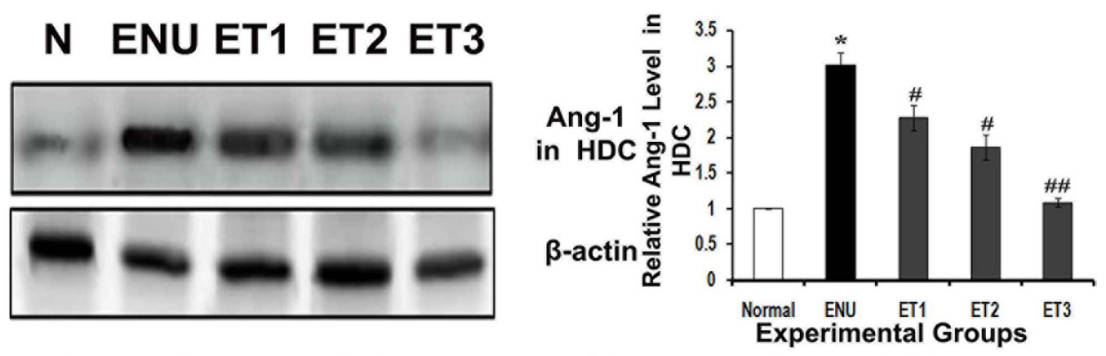

Comparison of Relative Ang-1Level between LDC and HDC

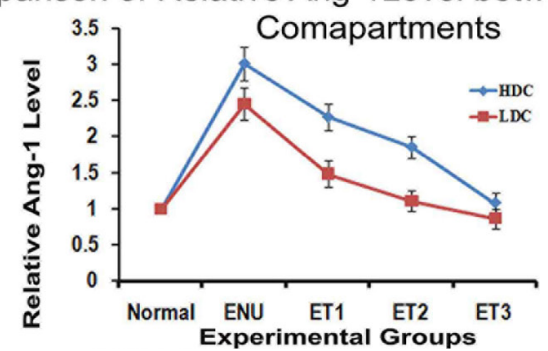




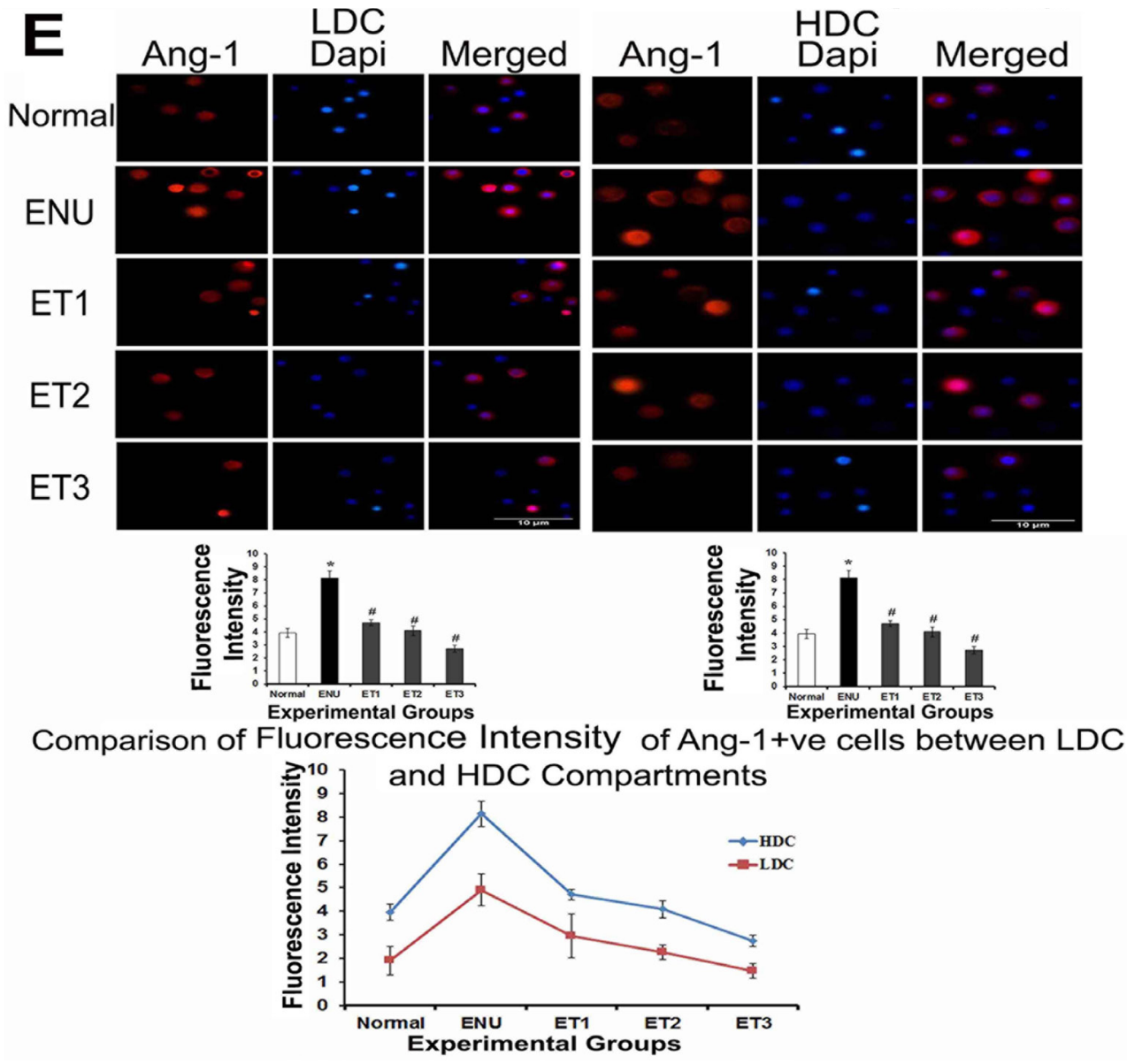

Figure 4. Comparative study of expression of Ang-1 in HSCs of five experimental animal groups, viz., the normal, healthy control rats $(\mathrm{N})$, glioma-bearing rats (ENU), and rats having received the first (ET1), second (ET2) and third (ET3) doses of T11TS. Flowcytometric studies of the expression of Ang-1 in HSCs cells isolated from bone marrow of normal controls and of glioma-bearing rats before and after T11TS treatment have been shown. A: Flowcytometric analysis of Ang-1 percent positive cells in the LDC using BD Cell Quest Pro Software by using scatter from a single representative experiment. The percentage of expression refers to the percent positive cells out of 10,000 cells analyzed represented in graphical in bar diagram. Column values represent mean \pm SD ( $n=6$ animals per group); B: Flowcytometric analysis of Ang-1 percent positive cells in the HDC using BD Cell Quest Pro Software by using scatter from a single representative experiment. The percentage of expression refers to the percent positive cells out of 10,000 cells analyzed represented in graphical form represented in bar diagram. Column values represent mean \pm SD ( $n=6$ animals per group). Comparison of distribution of Ang- $1^{+}$cells between LDC and HDC: Certain groups of stem cells, which probably attach to the osteoblastic niche show higher expression of Ang- $1^{+}$cells, indicating that quiescent state is being maintained in the Ang- $1^{+}$cells to protect them from pathological insults and fine tuning the self-renewal capacity. Here high level of expression in the glioma group might be due to the attempt to save the stem cell pool from the devastating effect of a chemical carcinogen ENU. The subsequent treatment with three doses of T11TS brings back both the HDC and LDC cells to bear normal levels of Ang-1; C: expression of Ang-1 in LDC was analyzed by immunoblotting using anti-Ang-1 specific antibody. The immunoblot shows band intensities for the Ang-1. $\beta$-actin was used as loading control and blots were reprobed with anti- $\beta$ actin antibody to establish equivalent loading. Bands were individually analyzed densitometrically and relative pixel intensities of individual, group were displayed in bar diagrams; D: expression of Ang-1 in HDC was analyzed by immunoblotting using anti-Ang-1 specific antibody. The immunoblot shows band intensities for the Ang-1. $\beta$-actin was used as loading control and blots were reprobed with anti- $\beta$ actin antibody to establish equivalent loading. Bands were individually analyzed densitometrically and relative pixel intensities of individual, group were displayed in bar diagrams; E: representative images (100× magnification) showing immunofluorescent staining of Ang-1 expression on bone marrow derived hematopoietic stem cells of normal $(\mathrm{N})$ and glioma-bearing rats before (ENU) and after T11TS treatment (ET1, ET2 and ET3 groups) in both the groups LDC and HDC. Each condition was observed in triplicate and six images were taken for each sample. Column Ang-1: TRITC stained Ang-1 expression in isolated BMHSC cells which appears red in color. Column Dapi: DAPI-stained nuclei appear blue. Column Merge: Merged picture TRITC fluorescence intensity of each group was analyzed with Nikon's Nis - Elements D3.00 software and the mean intensity was expressed in bar diagrams. Individual bar values represent mean intensity \pm SD of the respective group. ${ }^{*}$ Significant $(P<0.001)$ increase in ENU compared with that of normal control group. ${ }^{\#}$ Significant $(P<0.001)$ decrease, when individually comparing T11TS treated groups with glioma-bearing ENU group. At the bottom the comparison of the mean intensity of Ang-1 positive cells between LDC and HDC has been also depicted. HSCs: hematopoietic stem cells; LDC: low density compartment; HDC: high density compartments; ENU: N-ethyl-N-nitrosourea 
bearing group both in the LDC and HDC. Further, in situ immunofluorescence imaging studies [Figure 4E] of isolated BMHSCs showed a sharp $(P<0.001)$ increase in mean fluorescence intensity of cytoplasmic Ang-1 in HSCs of ENU induced glioma-bearing group compared to that in normal BMHSCs in both the immature and mature compartments which showed moderate fluorescence staining and hence the moderate mean intensity of fluorescence. However, T11TS treatment was able to bring down the fluorescence intensity of cytoplasmic Ang-1 in dose dependent manner $(P<0.001)$ in glioma-associated HSCs of ET1, ET2, and ET3 groups compared to that in HSCs of the glioma-bearing ENU group.

\section{T11TS therapy inhibits Tie-2 expression}

Flowcytometric studies showed [Figure 5A and B] that there was simultaneous remarkable $(P<0.001)$ elevated expression of Tie-2 in BMHSCs following glioma induction of the ENU group in both the compartments LDC and HDC compared to low basal expression in normal BMHSCs in both the LDC and HDC. T11TS therapy in glioma model, which significantly $(P<0.001)$ decreased Tie-2 expression in glioma associated BMHSCs of both LDC and HDC compartment in all the three ET1, ET2 and ET3 dose levels in dose dependent manner as compared to the remarkably high expression in ENU group both in the LDC and HDC.

In situ immunofluorescence staining of isolated BMHSCs of rats from different experimental groups showed that glioma induction in the ENU group caused a remarkable increase in Tie-2 expression [Figure 5C] in HSCs within bone marrow both in the LDC and HDC when compared to that in isolated HSCs from a normal control group in both the compartments. T11TS therapy caused a significant $(P<0.001)$ dosedependent down regulation of Tie-2 expression in glioma-bearing HSCs within the bone marrow of T11TS treated groups both in the LDC and HDC compartments.

Tie-2 expression pattern in glioma-associated BMHSCs as observed from flowcytometric studies concurred with the in-situ immunofluorescence imaging results.

\section{DISCUSSION}

There is global immune suppression during glioma growth. Intraperitoneal administration of ENU in 5-6 days old neonatal rats produce grade IV glioma after 5-6 months of age. The salient features of ENU induced full-blown grade IV glioma, have been elaborately elucidated histologically ${ }^{[56]}$, by Glial fibrillary acidic protein (GFAP) staining ${ }^{[57]}$, by cell proliferation index studies ${ }^{[58]}$, and by in situ immunofluorescences ${ }^{[59]}$. The published literature has also conclusively documented the gliomagenic global immune suppression on gliomabearing animals and the beneficial immunomodulatory effect of T11TS immunotherapy ${ }^{[60-63]}$. Following T11TS administration, there is profound immune stimulation which in turn results in the proliferation of the immunocytes and rejuvenates immune suppressive state of the malignant glioma ${ }^{[6,62,64-67]}$. Therefore, the novelty of our work is that this is the first reporting of the status of HSCs during glioma occurrence and thereafter following immunotherapy, which has not been explored so far. Both, in HDC comprised of mature cells and LDC composed of relatively immature cells, the suppressive effect on HSCs during a chemical carcinogen-induced glioma condition has been documented and reversal of this suppressive situation after T11TS administration has also been noted.

The Sialomucin CD34 is a critical marker for primitive HSCs, the expression pattern of which appears to be responsible for most of the early phases of hematopoietic activity ${ }^{[50,68]}$. Our study demonstrated that T11TS therapy significantly stimulates the level of expressions of CD34 both at the LDC and HDC in BMHSCs of glioma-bearing rats. The diminished level of $\mathrm{CD}_{3} 4^{+}$on HSCs of glioma-bearing animals indicates a diminution of primitive HSCs and suppression of normal hematopoiesis during glioma progression, which might be associated with the accelerated pre-mature apoptosis of the hematopoietic machinery due to the invading glioma ${ }^{[41]}$. From our experiments, it was delineated that LDC in all the experimental groups contains 
A

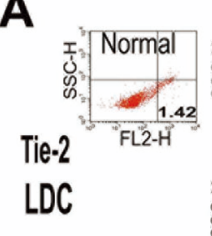

B

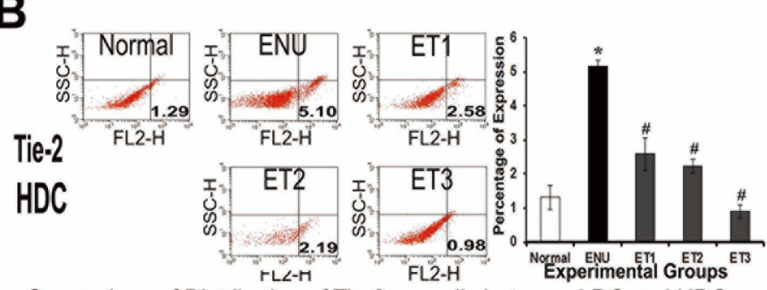

Comparison of Distribution of Tie-2+ve cells between LDC and HDC

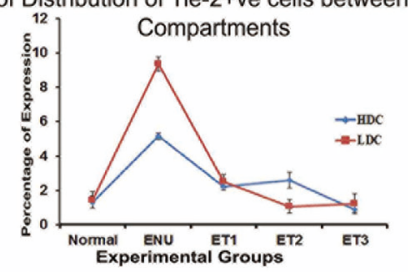

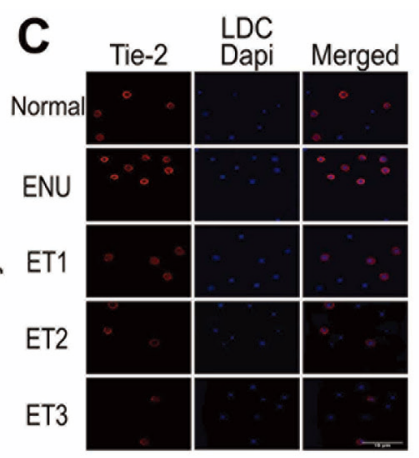

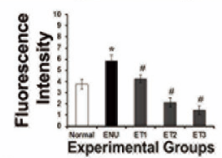

Comparison of Fluorescence Intensity of Tie+ve cells between LDC

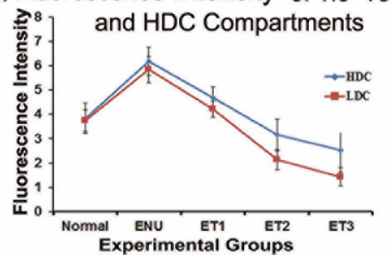

Figure 5. Comparative study of expression of Tie-2 in HSCs of five experimental animal groups, viz., normal, healthy control rats (N), glioma-bearing rats (ENU), and rats having received the first (ET1), second (ET2) and third (ET3) doses of T11TS. Flowcytometric studies of the expression of Tie-2 in HSCs cells isolated from bone marrow of normal control and of glioma-bearing rats before and after T11TS treatment have been shown. A: Flowcytometric analysis of Tie-2 percent positive cells in the LDC using BD Cell Quest Pro Software by using scatter from a single representative experiment. The percentage of expression refers to the percent positive cells out of 10,000 cells analyzed represented in graphical form in bar diagram. Column values represent mean $\pm \mathrm{SD}(n=6$ animals per group); B: Flowcytometric analysis of Tie-2 percent positive cells in the HDC using BD Cell Quest Pro Software by using scatter from a single representative experiment. The percentage of expression refers to the percent positive cells out of 10,000 cells analyzed represented in graphical form in bar diagram. Column values represent mean $\pm \mathrm{SD}\left(n=6\right.$ animals per group). Comparison of Distribution of Tie- $2^{+}$Cells between LDC and HDC: Tie-2 which is ligand to Ang-1 and is expressed on HSCs is highly expressed in the LDC group compared to the HDC in ENU treated groups, though both groups show up-regulated expression compared to the normal group. This shows that the immature HSCs are more protected than the mature cells at HDC during the ENU insult. T11Ts down regulates the higher expression of both the groups below normal levels, indicating that T11TS revive the quiescent state of HSCs driving them towards differentiation and self-renewal properties; C: representative images (100× magnification) showing immunofluorescent staining of Tie-2 expression on bone marrow derived hematopoietic stem cells of normal (N) and glioma-bearing rats before (ENU) and after T11TS treatment (ET1, ET2 and ET3 groups) in both the groups LDC and HDC. Each condition was observed in triplicate and six images were taken for each sample. Column Tie-2: TRITC stained Tie-2 expression in isolated BMHSC cells which appears red in color. Column Dapi: DAPI-stained nuclei appear blue. Column Merge: Merged picture TRITC fluorescence intensity of each group was analyzed with Nikon's Nis - Elements D3.00 software and the mean intensity was expressed in bar diagrams. Individual bar values represent mean intensity \pm SD of the respective group. *Significant $(P<0.001)$ increase in ENU compared with that of normal control group. "Significant $(P<0.001)$ decrease, when individually comparing T11TS treated groups with glioma-bearing ENU group. At the bottom the comparison of the mean intensity of Tie-2 positive cells between LDC and HDC has been also depicted. HSCs: hematopoietic stem cells; LDC: low density compartment; HDC: high density compartments; ENU: N-ethyl-N-nitrosourea

more immature $\mathrm{CD} 34^{+}$stem cells than the HDC [Figure $1 \mathrm{~A}$ and $\mathrm{B}$ ] which is perhaps due to migration and spontaneous differentiation of $\mathrm{CD} 34^{+}$stem cells from the HDC compartment towards further maturity. Moreover, compartmental mobilization of bone marrow cells under various pathological/physiological conditions is a routine phenomenon ${ }^{[69]}$. The result suggests that T11TS is able to stimulate glioma-associated HSC's revival from the niche with the regeneration of the $\mathrm{CD} 34^{+}$cells ${ }^{[41]}$.

With the aim to delineate mechanistic insights of T11TS immunotherapy on hematopoietic signaling system during gliomagenesis, we have further investigated another two important markers of HSCs, Sca-1 and c-kit known for their long-term stem cell activity ${ }^{[70]}$. 
Sca-1 or lymphocyte activation protein-6A (Ly-6 A/E) ${ }^{[7]}$ not only marks various developmental stages of $\mathrm{HSCs}^{[25]}$ but also plays an indispensable regulatory role during self-renewal for normal hematopoiesis ${ }^{[25,72]}$. In our experiment [Figure $2 \mathrm{~A}$ and $\mathrm{B}$ ], it has been observed that compared to the normal group, glioma induction causes a significant decrease of the level of Sca-1 both at LDC and HDC. Evaluation with normal counterparts, HDC population was shown to be lower than the population at LDC which might be due to impairment of normal transition of immature HSCs from LDC to HDC during glioma growth, ultimately resulting in a decrease in the maturity of Sca-1 $1^{+}$HSCs due to a negative feedback effect. During T11TS administration, there was a gradual increase in expressions of Sca-1 at all dose levels, both at LDC and HDC and a sharp increase in Sca-1 ${ }^{+}$cells after third dose of T11TS with higher level of expression in the LDC group as pointed out in the line diagram [Figure 2]. T11TS therapy not only promotes self-renewal of both the population of Sca-1 $1^{+}$cells but also hints towards further maturity. Phenotypic expression of Sca-1 distinguishes the stem cell compartment from committed myeloid and lymphoid progenitors, as its rapid down regulation was observed during differentiation ${ }^{[73]}$.

The proto-oncogene c-kit, a cell surface receptor tyrosine kinase and its ligand stem cell factor (SCF) play an essential role in intra-marrow hematopoiesis during adulthood ${ }^{[74]}$. C-kit is exclusively expressed in primitive HSCs to impart essential regulatory function during the early stages of hematopoiesis ${ }^{[75-77]}$. In vivo blocking of interaction between c-kit and SCF demote HSCs self-renewal by hindering the release of HSCs from the bone marrow. In our experiment [Figure $3 \mathrm{~A}$ and B], ENU mediated glioma induction causes a significant decrease of the expression level of c-kit both in the LDC and HDC as compared to the normal group, but after treatment with T11TS, the level gradually increased with the consecutive doses (ET1 and ET2), and the level of receptor expression is significantly higher than the glioma group and even higher than the normal group at the third dose (ET3) both in the LDC and HDC. In glioma-bearing animals, the lower expression level in the HDC as compared to LDC might be due to the preferential killing of comparatively mature cells that are expressing constitutively active c-kit in terms of the active form of the cell cycle in the HDC sparing immature more primitive dormant progenitors ${ }^{[78]}$. Further, the comparative line diagram [Figure 3] shows simultaneous up-regulation of c-kit ${ }^{+}$cells in the HDC as compared to LDC of T11TS treated groups, indicating that the primitive immature progenitors have a lower c-kit expression as compared to their mature descendants in the HDC having higher c-kit expression. The observation further confirms the notion that as immature primitive cells enter the phase of maturation, divide actively and initiate the phase of differentiation, the expression of c-kit intensifies ${ }^{[79,80]}$. This is perhaps due to the fact that the high expression pattern of c-kit opens up SCF signaling cascade to guide the HSCs towards lineage commitment where SCF may influence the migration of hematopoietic stem cells to their ultimate destinations of development.

Both short-term and long-term repopulating HSCs reside within the $\mathrm{CD} 34^{+}$, Sca- $1^{+}$and c-kit ${ }^{+}$bone marrow population ${ }^{[81]}$. During normal physiological condition, a fine tune between self-renewal and differentiation is able to maintain the constant number of HSCs. However, disease conditions such as anemia, cancer or during myelotoxic chemotherapy have been evidence of alteration of total stem cell number indicating that the counterbalance between self-renewal and differentiation can reconcile as per physiological needs ${ }^{[82,83]}$. This pliability is most likely achieved by molecular crosstalk between stem cells and their specific microenvironment called the niche. This reciprocal intracellular interaction between HSCs and bone marrow niche also regulates the status of HSCs and influences their surface phenotypes. On the other hand, the quiescent state of hematopoietic stem cells is thought to be critical in sustaining a self-renewing HSC compartment for life and to shield the stem cell pool from premature exhaustion during various pathological conditions. Indeed, the maintenance of quiescent state and slow cell-cycle progression of HSCs could directly be linked to the robust reconstitution ability and longterm sustainability ${ }^{[84]}$. In addition, quiescent HSC populations are resistant to 5 -fluorouracil-induced 
myelosuppression ${ }^{[28]}$, suggesting that the quiescence of HSCs is closely associated with the protection of the HSC pool from the various stresses induced by myelotoxic insults. However, precise regulatory mechanisms of niche cell-HSCs remain elusive.

Ang-1 expressed by niche cell is one of the indispensable interacting molecules which function as an autocrine activating factor for Tie-2 signaling in HSCs and their interaction activates $\beta 1$-integrin and $\mathrm{N}$-cadherin, enhances quiescent state and facilitates long-term repopulating activity of HSCs by facilitating induced adhesion to bone and homing during the physiological crisis. The critical regulatory role of Ang-1/ Tie-2 signaling in the maintenance of HSCs quiescence and promoting their adhesion to bone marrow niche, resulting in protection of HSCs compartment from myelosuppressive insults has been documented before ${ }^{[28]}$. Furthermore, the mechanistic insight of this protective interaction against apoptosis by activating the PI3K pathway has also been addressed ${ }^{[85]}$. We have also documented the inhibitory role of T11TS on glioma mediated pro-angiogenic Ang-1/Tie-2 signaling within brain endothelial cells ultimately restraining pro-tumorigenic angiogenesis in rodent glioma mode ${ }^{[86]}$. Although the mechanism through which glioma modulated activation of Ang-1/Tie-2 signaling within bone marrow niche and their correlation with gliomagenic global immune suppression remain to be elucidated, we hypothesize that gliomagenic up regulation of Ang-1/Tie-2 interaction disrupts the normal hematopoietic synchrony and ultimately affect the lymphohematopoiesis.

Over expression of Ang- $1^{+}$cells at osteoblastic niche signifying the quiescent state of HSCs as a protective barrier during pathological conditions to fine tune the self-renewal capacity. Here [Figure $4 \mathrm{~A}$ and B], high level of expression in the glioma group might be due to the attempt to save the stem cell pool from the devastating effect of the chemical carcinogen ENU. The subsequent treatment with three doses of T11TS brings back both the HDC and LDC cells to near normal levels of Ang-1. The above mentioned effect of Ang-1on HSCs in the glioma-bearing state is definitely mediated by over expression of Tie-2 as Ang-1 is believed to be the dominant ligand for Tie-2 receptor in LT-BMHSCs and contributed in sustenance of stem cell activities within the bone marrow niche ${ }^{[87]}$. In our finding [Figure $5 \mathrm{~A}$ and $\mathrm{B}$ ] higher expression of Tie-2 at LDC compared to HDC in ENU treated groups as compared to normal group hint to their protective effect on the immature HSCs than the mature cells at HDC during ENU insult. T11TS down regulates the higher expression of Tie-2 from both the mature and immature hematopoietic cells below normal levels, indicating that T11TS revive the quiescent state of HSCs driving them towards normal hematopoiesis of reconstitution and self-renewal.

In summary, our current investigation clearly demonstrated for the first time, that during glioma condition, there was significant disruption in early phases of hematopoietic cell signaling. Our phenotypic studies of the two compartments of HSCs comprising immature LDC and mature HDC cells indicate that during glioma development all the receptors in both the compartments are drastically reduced due to reversion to the quiescent state of the particular population and also cell loss due to apoptosis as hinted in our recent publication ${ }^{[4]}$. Their regenerative capacities were all renewed by T11TS treatment rendering "Therapeutically equipped HSC". Primarily the immature cells had been stimulated from the quiescent state as shown by CD34 up-regulation. Next, they were driven towards maturity as denoted by Sca-1 upregulation and lastly c-kit up regulations indicating the signaling involvements towards progenitor cell development. Up-regulation of the niche receptor Ang-1 and its counter-receptors Tie-2 of HSCs in the glioma group and drastic down regulation of both the stem cell pool by T11TS confirms the protective effect of T11TS to facilitate revival from the quiescent state of HSCs driving them towards differentiation and self-renewal properties [Figure 6]. Our findings should provide helpful guidance for the therapeutic utilization of T11TS during glioma and will also facilitate the understanding of how HSCs behave during gliomagenic immunological shock. 
Glioma mediated Hibernation of HSC and Global Immune Suppression

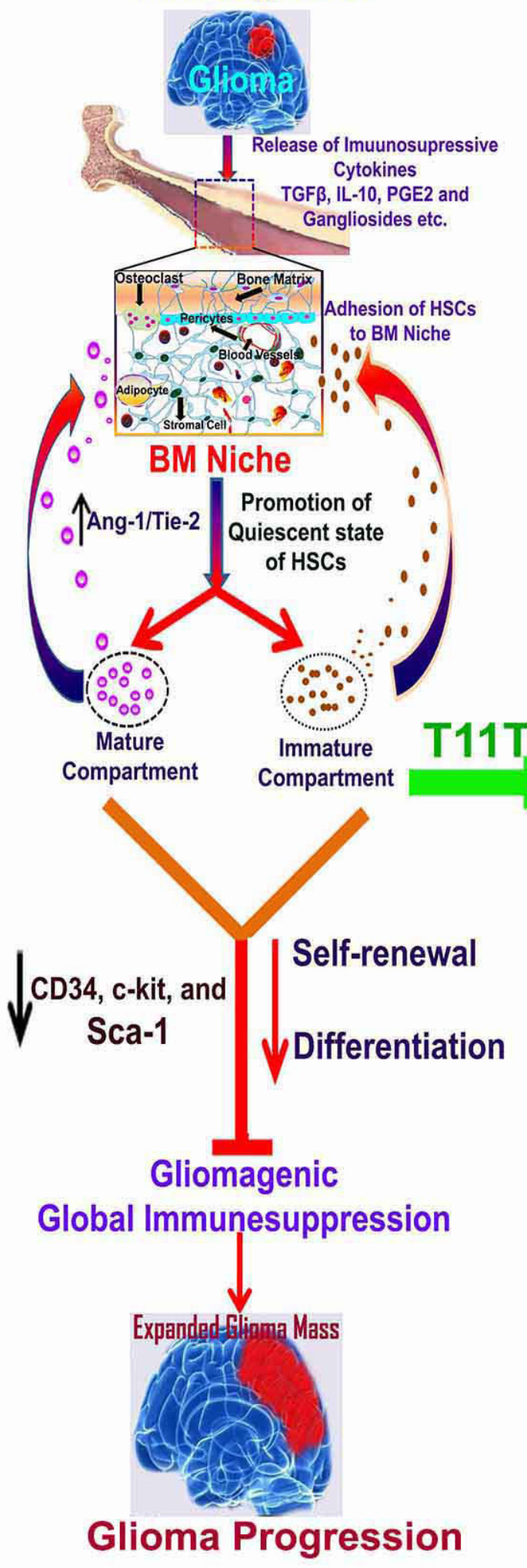

T11TS mediated rejuvenation of HSC leading to immune potentiation
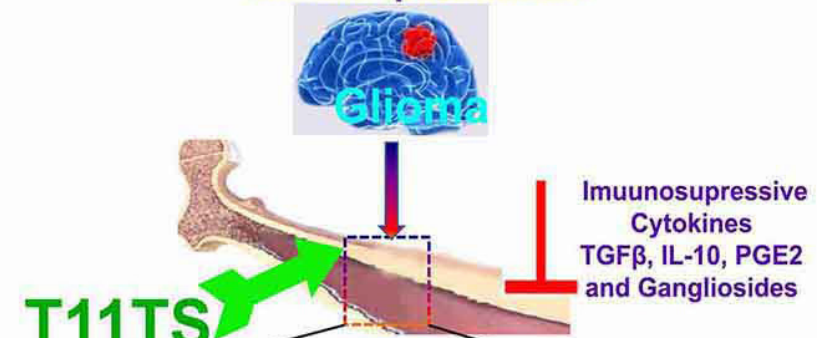

T11TS
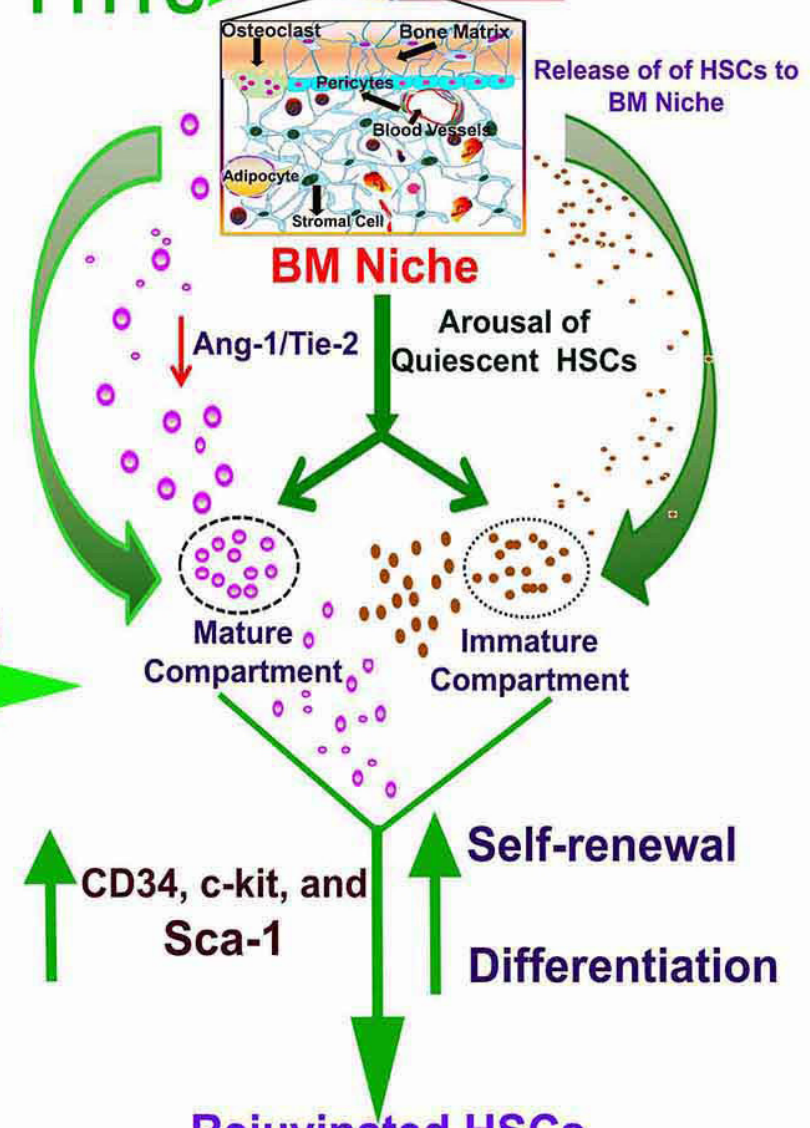

Rejuvinated HSCs

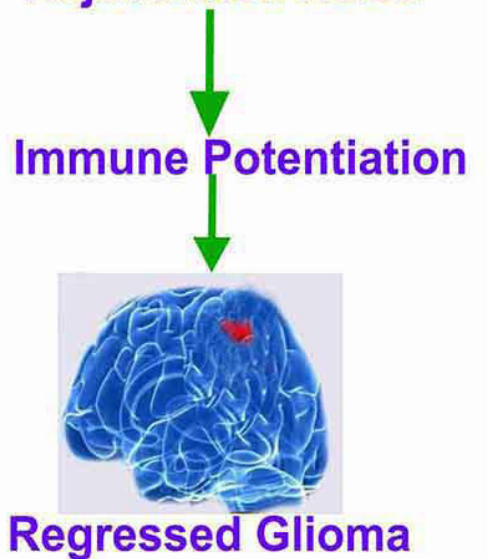

Figure 6. Proposed pathway of gliomagenic alteration of expression pattern of important early phase phenotypic markers in ENU induced glioma-bearing rats and their modulation following T11TS therapy hints towards immunocompetence against immune suppressive glioma. ENU: N-ethyl-N-nitrosourea 


\section{DECLARATIONS}

\section{Acknowledgements}

The authors are grateful to Prof. Samaresh Chaudhuri for his inspiration and overall guidance to take up this study and to Prof. Nandita Basu, Director, Calcutta School of Tropical Medicine, for providing all the facilities required for the study. The authors are also thankful to West Bengal University of Health Sciences for their kind approval to pursue this study.

\section{Authors' contributions}

Conducted experiments and provided results: Mondal S, Datta A, Hazra I, Omar Faruk SM, Moitra S, Chaudhuri S, Nath L, Das PK, Basu AK

Co-wrote the first draft: Mondal S

Edited the manuscript: Chaudhuri S

Co-supervised aspects of the project: Tripathi SK

Provided overall supervision of the project, edited and finalized the manuscript: Chaudhuri S

\section{Availability of data and materials}

Not applicable.

\section{Financial support and sponsorship}

This work has been supported by a research grant (Sanction Order for Grant-in-Aid No 563-BT (Estt.)/RD3/13 dated 23.08.2013) from the West Bengal Department of Biotechnology, Government of West Bengal.

\section{Conflicts of interest}

All authors declared that there are no conflicts of interest.

\section{Ethical approval and consent to participate}

All studies involving animals were reviewed and approved by Institutional Ethical Committee at Calcutta School of Tropical Medicine, Kolkata, West Bengal, India, monitored by Committee for the Purpose of Control and Supervision of Experiments on Animals, Govt. of India (CPCSEA) regulations.

\section{Consent for publication}

Not applicable.

\section{Copyright}

(c) The Author(s) 2018.

\section{REFERENCE}

1. Waziri A. Glioblastoma-derived mechanisms of systemic immunosuppression. Neurosurg Clin N Am 2010;21:31-42.

2. Taniguchi Y, Ono K, Yoshida S, Tanaka R. Antigen-presenting capability of glial cells under glioma-harboring conditions and the effect of glioma-derived factors on antigen presentation. J Neuroimmunol 2000;111:177-85.

3. Bloch O, Crane CA, Kaur R, Safaee M, Rutkowski MJ, Parsa AT. Gliomas promote immunosuppression through induction of B7-H1 expression in tumor-associated macrophages. Clin Cancer Res 2013;19:3165-75.

4. Castro MG, Baker GJ, Lowenstein PR. Blocking immunosuppressive checkpoints for glioma therapy: the more the Merrier! Clin Cancer Res 2014;20:5147-9.

5. Fecci PE, Ochiai H, Mitchell DA, Grossi PM, Sweeney AE, Archer GE, Cummings T, Allison JP, Bigner DD, Sampson JH. Systemic CTLA-4 blockade ameliorates glioma-induced changes to the CD4+ T cell compartment without affecting regulatory T-cell function. Clin Cancer Res 2007;13:2158-67.

6. Zhang Y, Wang C, Zhang Y, Sun M. C6 glioma cells retrovirally engineered to express IL-18 and Fas exert FasL-dependent cytotoxicity against glioma formation. Biochem Biophys Res Commun 2004;325:1240-5.

7. Crane CA, Ahn BJ, Han SJ, Parsa AT. Soluble factors secreted by glioblastoma cell lines facilitate recruitment, survival, and expansion of regulatory T cells: implications for immunotherapy. Neuro Oncol 2012;14:584-95. 
8. Zagzag D, Salnikow K, Chiriboga L, Yee H, Lan L, Ali MA, Garcia R, Demaria S, Newcomb EW. Downregulation of major histocompatibility complex antigens in invading glioma cells: stealth invasion of the brain. Lab Invest 2005;85:328-41.

9. Jackson C, Ruzevick J, Phallen J, Belcaid Z, Lim M. Challenges in immunotherapy presented by the glioblastoma multiforme microenvironment. Clin Dev Immunol 2011;2011:732413.

10. Hao C, Parney IF, Roa WH, Turner J, Petruk KC, Ramsay DA. Cytokine and cytokine receptor mRNA expression in human glioblastomas: evidence of Th1, Th2 and Th3 cytokine dysregulation. Acta Neuropathol 2002;103:171-8.

11. Chahlavi A, Rayman P, Richmond AL, Biswas K, Zhang R, Vogelbaum M, Tannenbaum C, Barnett G, Finke JH. Glioblastomas induce T-lymphocyte death by two distinct pathways involving gangliosides and CD70. Cancer Res 2005;65:5428-38.

12. Kast RE, Hill QA, Wion D, Mellstedt H, Focosi D, Karpel-Massler G, Heiland T, Halatsch ME. Glioblastoma-synthesized G-CSF and GM-CSF contribute to growth and immunosuppression: potential therapeutic benefit from dapsone, fenofibrate, and ribavirin. Tumour Biol 2017;39:1010428317699797.

13. Kamran N, Kadiyala P, Saxena M, Candolfi M, Li Y, Moreno-Ayala MA, Raja N, Shah D, Lowenstein PR, Castro MG. Immunosuppressive Myeloid Cells' Blockade in the glioma microenvironment enhances the efficacy of immune-stimulatory gene therapy. Mol Ther 2017;25:232-48.

14. Blank U, Karlsson S. TGF-beta signaling in the control of hematopoietic stem cells. Blood 2015;125:3542-50.

15. Chabanon A, Desterke C, Rodenburger E, Clay D, Guerton B, Boutin L, Bennaceur-Griscelli A, Pierre-Louis O, Uzan G, Abecassis L, Bourgeade MF, Lataillade JJ, Le Bousse-Kerdiles MC. A cross-talk between stromal cell-derived factor-1 and transforming growth factor-beta controls the quiescence/cycling switch of $\mathrm{CD} 34(+)$ progenitors through $\mathrm{FoxO} 3$ and mammalian target of rapamycin. Stem Cells 2008;26:3150-61.

16. Bharti AC, Singh SM. Induction of apoptosis in bone marrow cells by gangliosides produced by a $\mathrm{T}$ cell lymphoma. Immunol Lett 2000;72:39-48.

17. Bharti AC, Singh SM. Gangliosides derived from a T cell lymphoma inhibit bone marrow cell proliferation and differentiation. Int Immunopharmacol 2001;1:155-65.

18. Gentile PS, Pelus LM. In vivo modulation of myelopoiesis by prostaglandin E2. IV. Prostaglandin E2 induction of myelopoietic inhibitory activity. J Immunol 1988;141:2714-20.

19. Kurland J, Moore MA. Modulation of hemopoiesis by prostaglandins. Exp Hematol 1977;5:357-73.

20. Geissler K, Jager E, Ohler L, Gisslinger H, Jager U, Lechner K. Interleukin-10 inhibits autonomous myelopoiesis in patients with myelofibrosis. Eur J Haematol 2015;95:239-43.

21. Oehler L, Kollars M, Bohle B, Berer A, Reiter E, Lechner K, Geissler K. Interleukin-10 inhibits burst-forming unit-erythroid growth by suppression of endogenous granulocyte-macrophage colony-stimulating factor production from T cells. Exp Hematol 1999;27:217-23.

22. King KY, Goodell MA. Inflammatory modulation of HSCs: viewing the HSC as a foundation for the immune response. Nat Rev Immunol 2011;11:685-92.

23. Eskandary H, Basiri M, Nematollahi-Mahani SN, Mehravaran S. The role of stem cells in tumor targeting and growth suppression of gliomas. Biologics 2011;5:61-70.

24. Kim SH, Kwon CH, Nakano I. Detoxification of oxidative stress in glioma stem cells: mechanism, clinical relevance, and therapeutic development. J Neurosci Res 2014;92:1419-24.

25. Bradfute SB, Graubert TA, Goodell MA. Roles of Sca-1 in hematopoietic stem/progenitor cell function. Exp Hematol 2005;33:836-43.

26. Deshpande S, Bosbach B, Yozgat Y, Park CY, Moore MA, Besmer P. KIT receptor gain-of-function in hematopoiesis enhances stem cell self-renewal and promotes progenitor cell expansion. Stem Cells 2013;31:1683-95.

27. Katayama N, Shih JP, Nishikawa S, Kina T, Clark SC, Ogawa M. Stage-specific expression of c-kit protein by murine hematopoietic progenitors. Blood 1993;82:2353-60.

28. Arai F, Hirao A, Ohmura M, Sato H, Matsuoka S, Takubo K, Ito K, Koh GY, Suda T. Tie2/Angiopoietin-1 signaling regulates hematopoietic stem cell quiescence in the bone marrow niche. Cell 2004;118:149-61.

29. Ikushima YM, Arai F, Nakamura Y, Hosokawa K, Kubota Y, Hirashima M, Toyama H, Suda T. Enhanced Angpt1/Tie2 signaling affects the differentiation and long-term repopulation ability of hematopoietic stem cells. Biochem Biophys Res Commun 2013;430:20-5.

30. Springer TA, Dustin ML, Kishimoto TK, Marlin SD. The lymphocyte function-associated LFA-1, CD2, and LFA-3 molecules: cell adhesion receptors of the immune system. Annu Rev Immunol 1987;5:223-52.

31. Sarkar S, Begum Z, Dutta S, Dutta SK, Chaudhuri S, Chaudhuri S. Sheep form of leucocyte function antigen-3 (T11TS) exerts immunostimulatory and anti-tumor activity against experimental brain tumor. A new approach to biological response modifier therapy. J Exp Clin Cancer Res 2002;21:95-106.

32. Giegerich GW, Hein WR, Miyasaka M, Tiefenthaler G, Hunig T. Restricted expression of CD2 among subsets of sheep thymocytes and T lymphocytes. Immunology 1989;66:354-61.

33. Hunig T, Tiefenthaler G, Mitnacht R, Kohler C, Lottspeich F, Meuer S. The "erythrocyte receptor" of T-lymphocytes and T11 target structure (T11TS): complementary cell interaction molecules involved in T-cell activation. Behring Inst Mitt 1987:31-40.

34. Kumar P, Chatterjee S, Acharya S, Kumari A, Chaudhuri S, Singh MK, Ghosh SN, Chaudhuri S. Significant modulation of macrophages associated cytokines TNF-alpha, VEGF and apoptotoic protein Bax, Bcl2 abrogates tumor cells. Cell Immunol 2013;284:172-81.

35. Begum Z, Ghosh A, Sarkar S, Mukherjee J, Mazumdar M, Sarkar P, Chaudhuri S. Documentation of immune profile of microglia through cell surface marker study in glioma model primed by a novel cell surface glycopeptide T11TS/SLFA-3. Glycoconj J 2004;20:515-23.

36. Bhattacharjee M, Acharya S, Ghosh A, Sarkar P, Chatterjee S, Kumar P, Chaudhuri S. Bax and Bid act in synergy to bring about 
T11TS-mediated glioma apoptosis via the release of mitochondrial cytochrome c and subsequent caspase activation. Int Immunol 2008;20:1489-505.

37. Chaudhuri S, Singh MK, Bhattacharya D, Datta A, Hazra I, Mondal S, Faruk Sk Md O, Ronsard L, Ghosh TK, Chaudhuri S. T11TS immunotherapy repairs PI3K-AKT signaling in T-cells: clues toward enhanced T-cell survival in rat glioma model. J Cell Physiol 2018;233:759-70.

38. Chaudhuri S, Bhattacharya D, Singh MK, Moitra S, Ronsard L, Ghosh TK, Chaudhuri S. Disease relevance of T11TS-induced T-cell signal transduction through the CD2-mediated calcineurin-NFAT pathway: perspectives in glioma immunotherapy. Mol Immunol 2015;67:256-64.

39. Mukherjee J, Ghosh A, Ghosh A, Chaudhuri S. ENU administration causes genomic instability along with single nucleotide polymorphisms in p53 during gliomagenesis: T11TS administration demonstrated in vivo apoptosis of these genetically altered tumor cells. Cancer Biol Ther 2006;5:156-64.

40. Mukherjee J, Ghosh A, Sarkar S, Mazumdar M, Sarkar P, Duttagupta AK, Chaudhuri S. T11TS/S-LFA3 induces apoptosis of the brain tumor cells: a new approach to characterise the apoptosis associated genetic changes by arbitrarily primed-PCR. Cancer Lett 2005;222:23-38.

41. Mondal S, Hazra I, Datta A, Sk Md OF, Moitra S, Tripathi SK, Chaudhuri S. T11TS repress gliomagenic apoptosis of bone marrow hematopoietic stem cells. J Cell Physiol 2018;233:269-90.

42. Druckrey H, Ivankovic S, Gimmy J. Cancerogenic effects of methyl- and ethyl-nitrosourea (MNU and ENU) at single intracerebral and intracarotidal injection in newborn and young BD-rats. Z Krebsforsch Klin Onkol Cancer Res Clin Oncol 1973;79:282-97.

43. Singer B, Dosanjh MK. Site-directed mutagenesis for quatitation of base base interactions at defined sites. Mutat Res 1990;233:45-51.

44. Branstetter DG, Stoner GD, Schut HAJ, Senitzer D, Conran PB, Goldblatt PJ. Ethylnitrosourea-induced transplacental carcinogenesis in the mouse: tumor response, DNA binding, and adduct formation. Cancer Research 1987;47:348-52.

45. Ghosh A, Bhattacharya M, Sarkar P, Acharya S, Chaudhuri S. T11 target structure exerts effector function by activating immune cells in CNS against glioma where cytokine modulation provide favorable microenvironment. Indian J Exp Biol 2010;48:879-88.

46. Chatterjee S, Dutta RK, Basak P, Das P, Das M, Pereira JA, Chaklader M, Chaudhuri S, Law S. Alteration in marrow stromal microenvironment and apoptosis mechanisms involved in aplastic anemia: an animal model to study the possible disease pathology. Stem Cells Int 2010;2010:932354.

47. Bhattacharya D, Singh MK, Chaudhuri S, Acharya S, Basu AK, Chaudhuri S. T11TS impedes glioma angiogenesis by inhibiting VEGF signaling and pro-survival PI3K/Akt/eNOS pathway with concomitant upregulation of PTEN in brain endothelial cells. J Neurooncol 2013;113:13-25.

48. Law S, Maiti D, Palit A, Majumder D, Basu K, Chaudhuri S, Chaudhuri S. Facilitation of functional compartmentalization of bone marrow cells in leukemic mice by biological response modifiers: an immunotherapeutic approach. Immunol Lett 2001;76:145-52.

49. Civin CI, Banquerigo ML, Strauss LC, Loken MR. Antigenic analysis of hematopoiesis. VI. Flow cytometric characterization of My10-positive progenitor cells in normal human bone marrow. Exp Hematol 1987;15:10-7.

50. Sutherland DR, Keating A. The CD34 antigen: structure, biology, and potential clinical applications. J Hematother 1992;1:115-29.

51. Ito CY, Li CY, Bernstein A, Dick JE, Stanford WL. Hematopoietic stem cell and progenitor defects in Sca-1/Ly-6A-null mice. Blood 2003;101:517-23.

52. Sogo S, Inaba M, Ogata H, Hisha H, Adachi Y, Mori S, Toki J, Yamanishi K, Kanzaki H, Adachi M, Ikehara S. Induction of c-kit molecules on human $\mathrm{CD} 34+/ \mathrm{c}-\mathrm{kit}<$ low cells: evidence for $\mathrm{CD} 34+/ \mathrm{c}-\mathrm{kit}<$ low cells as primitive hematopoietic stem cells. Stem Cells 1997;15:420-9.

53. Ema H, Takano H, Sudo K, Nakauchi H. In vitro self-renewal division of hematopoietic stem cells. J Exp Med 2000;192:1281-8.

54. Shin JY, Hu W, Naramura M, Park CY. High c-Kit expression identifies hematopoietic stem cells with impaired self-renewal and megakaryocytic bias. J Exp Med 2014;211:217-31.

55. Yokota T, Oritani K, Butz S, Ewers S, Vestweber D, Kanakura Y. Markers for hematopoietic stem cells: histories and recent achievements. In: Advances in Hematopoietic Stem Cell Research. Mexico City: InTech; 2012. p.77-88.

56. Mukherjee J, Sarkar S, Ghosh A, Duttagupta AK, Chaudhuri S, Chaudhuri S. Immunotherapeutic effects of T11TS/S-LFA3 against nitrosocompound mediated neural genotoxicity. Toxicol Lett 2004;150:239-57.

57. Ghosh A, Mukherjee J, Bhattacharjee M, Sarkar P, Acharya S, Chaudhuri S. T11TS/SLFA-3 differentially regulate the population of microglia and brain infiltrating lymphocytes to reduce glioma by modulating intrinsic Bcl-2 expression rather than p53. Cent Nerv Syst Agents Med Chem 2007;7:145-55.

58. Acharya S, Chatterjee S, Kumar P, Bhattacharjee M, Chaudhuri S, Chaudhuri S. Induction of G1 arrest in glioma cells by T11TS is associated with upregulation of Cip1/Kip1 and concurrent downregulation of cyclin D (1 and 3). Anticancer Drugs 2010;21:53-64.

59. Singh MK, Bhattacharya D, Chaudhuri S, Acharya S, Kumar P, Santra P, Basu AK, Chaudhuri S. T11TS inhibits glioma angiogenesis by modulation of MMPs, TIMPs, with related integrin alphav and TGF-beta1 expressions. Tumour Biol 2014;35:2231-46.

60. Sarkar S, Ghosh A, Mukherjee J, Chaudhuri S, Chaudhuri S. CD2-SLFA3/T11TS interaction facilitates immune activation and glioma regression by apoptosis. Cancer Biol Ther 2004;3:1121-8.

61. Mukherjee J, Ghosh A, Sarkar P, Mazumdar M, Banerjee C, Chaudhuri S. Immunotherapy with T11TS/S-LFA-3 specifically induces apoptosis of brain tumor cells by augmenting intracranial immune status. Anticancer Res 2005;25:2905-19.

62. Ghosh A, Bhattacharya M, Sarkar P, Acharya S, Chaudhuri S. T11 target structure exerts effector function by activating immune cells in CNS against glioma where cytokine modulation provide favorable microenvironment. Indian J Exp Biol 2010;48:879-88.

63. Kumar P, Chatterjee S, Acharya S, Kumari A, Chaudhuri S, Singh MK, Ghosh SN, Chaudhuri S. Significant modulation of macrophages 
associated cytokines TNF-alpha, VEGF and apoptotoic protein Bax, Bcl2 abrogates tumor cells. Cell Immunol 2013;284:172-81.

64. Bhattacharjee M, Acharya S, Ghosh A, Sarkar P, Chatterjee S, Kumar P, Chaudhuri S. Bax and Bid act in synergy to bring about T11TS-mediated glioma apoptosis via the release of mitochondrial cytochrome $\mathrm{c}$ and subsequent caspase activation. Int Immunol 2008;20:1489-505.

65. Bhattacharya D, Singh MK, Chaudhuri S, Datta A, Chaudhuri S. T11TS treatment augments apoptosis of glioma associated brain endothelial cells, hint toward anti-angiogenic action in glioma. J Cell Physiol 2017;232:526-39.

66. Mukherjee J, Sarkar S, Ghosh A, Duttagupta AK, Chaudhuri S, Chaudhuri S. Immunotherapeutic effects of T11TS/S-LFA3 against nitrosocompound mediated neural genotoxicity. Toxicol Lett 2004;150:239-57.

67. Begum Z, Ghosh A, Sarkar S, Mukherjee J, Mazumdar M, Sarkar P, Chaudhuri S. Documentation of immune profile of microglia through cell surface marker study in glioma model primed by a novel cell surface glycopeptide T11TS/SLFA-3. Glycoconj J 2003;20:515-23.

68. Stella CC, Cazzola M, De FP, De VA, Gianni AM, Lanza F, Lauria F, Lemoli RM, Tarella C, Zanon P. CD34-positive cells: biology and clinical relevance. Haematologica 1995;80:367-87.

69. Potten CS, Loeffler M. Stem cells: attributes, cycles, spirals, pitfalls and uncertainties. Lessons for and from the crypt. Development 1990;110:1001-20.

70. Osawa M, Hanada K, Hamada H, Nakauchi H. Long-term lymphohematopoietic reconstitution by a single CD34-low/negative hematopoietic stem cell. Science 1996;273:242-5.

71. Holmes C, Stanford WL. Concise review: stem cell antigen-1: expression, function, and enigma. Stem Cells 2007;25:1339-47.

72. Walasek MA, Bystrykh LV, Olthof S, de HG, van OR. Sca-1 is an early-response target of histone deacetylase inhibitors and marks hematopoietic cells with enhanced function. Exp Hematol 2013;41:113-23.

73. Harman BC, Northrup DL, Allman D. Resolution of unique Sca-1highc-Kit- lymphoid-biased progenitors in adult bone marrow. J Immunol 2008;181:7514-24.

74. Orschell-Traycoff CM, Hiatt K, Dagher RN, Rice S, Yoder MC, Srour EF. Homing and engraftment potential of Sca-1(+)lin(-) cells fractionated on the basis of adhesion molecule expression and position in cell cycle. Blood 2000;96:1380-7.

75. Simmons PJ, Aylett GW, Niutta S, To LB, Juttner CA, Ashman LK. C-kit is expressed by primitive human hematopoietic cells that give rise to colony-forming cells in stroma-dependent or cytokine-supplemented culture. Exp Hematol 1994;22:157-65.

76. Ogawa M, Matsuzaki Y, Nishikawa S, Hayashi S, Kunisada T, Sudo T, Kina T, Nakauchi H, Nishikawa S. Expression and function of c-kit in hemopoietic progenitor cells. J Exp Med 1991;174:63-71.

77. Katayama N, Clark SC, Ogawa M. Growth factor requirement for survival in cell-cycle dormancy of primitive murine lymphohematopoietic progenitors. Blood 1993;81:610-6.

78. Okada S, Nakauchi H, Nagayoshi K, Nishikawa S, Nishikawa S, Miura Y, Suda T. Enrichment and characterization of murine hematopoietic stem cells that express c-kit molecule. Blood 1991;78:1706-12.

79. Henrich CJ, Goncharova EI, Wilson JA, Gardella RS, Johnson TR, McMahon JB, Takada K, Bokesch HR, Gustafson KR. Natural products active in aberrant c-Kit signaling. Chem Biol Drug Des 2007;69:321-30.

80. Lian Z, Toki J, Yu C, Hayashi H, Yasumizu R, Sugiura K, Jin T, Inaba M, Hisha H, Li Y, Yu W, Fan H, Ikehara S. Intrathymically injected hemopoietic stem cells can differentiate into all lineage cells in the thymus: differences between c-kit + cells and c-kit $<$ low cells. Stem Cells 1997;15:430-6.

81. Weissman IL, Anderson DJ, Gage F. Stem and progenitor cells: origins, phenotypes, lineage commitments, and transdifferentiations. Annu Rev Cell Dev Biol 2001;17:387-403.

82. Morrison SJ, Wright DE, Weissman IL. Cyclophosphamide/granulocyte colony-stimulating factor induces hematopoietic stem cells to proliferate prior to mobilization. Proc Natl Acad Sci U S A 1997;94:1908-13.

83. Weissman IL. Stem cells: units of development, units of regeneration, and units in evolution. Cell 2000;100:157-68.

84. Arai F, Hirao A, Suda T. Regulation of hematopoietic stem cells by the niche. Trends Cardiovasc Med 2005;15:75-9.

85. Arai F, Suda T. Quiescent stem cells in the niche. Cambridge (MA): Harvard Stem Cell Institute; 2008.

86. Bhattacharya D, Chaudhuri S, Singh MK, Chaudhuri S. T11TS inhibits Angiopoietin-1/Tie-2 signaling, EGFR activation and Raf/MEK/ ERK pathway in brain endothelial cells restraining angiogenesis in glioma model. Exp Mol Pathol 2015;98:455-66.

87. Gomei Y, Nakamura Y, Yoshihara H, Hosokawa K, Iwasaki H, Suda T, Arai F. Functional differences between two Tie2 ligands, Angiopoietin-1 and -2, in regulation of adult bone marrow hematopoietic stem cells. Exp Hematol 2010;38:82-9. 